\title{
Accounting for Spatial Complexities in the Calculation of Biological Reference Points: Effects of Misdiagnosing Population Structure for Stock Status Indicators
}

\begin{tabular}{|r|l|}
\hline Journal: & Canadian Journal of Fisheries and Aquatic Sciences \\
\hline Manuscript ID & cjfas-2016-0290.R1 \\
\hline Manuscript Type: & Article \\
\hline Date Submitted by the Author: & 23-Nov-2016 \\
\hline Keywlete List of Authors: & $\begin{array}{l}\text { Goethel, Daniel; Southeast Fisheries Science Center, } \\
\text { Berger, Aaron; NOAA-NMFS, FRAM }\end{array}$ \\
\hline & $\begin{array}{l}\text { POPULATION STRUCTURE < General, SPATIAL ANALYSIS < General, } \\
\text { FISHERY MANAGEMENT < General, STOCK ASSESSMENT < General, } \\
\text { MOVEMENT < General }\end{array}$ \\
\hline \multicolumn{2}{|c}{} \\
\hline
\end{tabular}


1 Title: Accounting for Spatial Complexities in the Calculation of Biological

Reference Points: Effects of Misdiagnosing Population Structure for Stock

\section{Status Indicators}

4

5 Running Title: Impact of spatial stock structure on the calculation of biological reference points 6

Daniel R. Goethel ${ }^{\mathrm{a}, 1}$ and Aaron M. Berger ${ }^{\mathrm{b}}$

$10{ }^{\text {a }}$ Sustainable Fisheries Division, Southeast Fisheries Science Center, National Marine Fisheries

11 Service, National Ocean and Atmospheric Administration, 75 Virginia Beach Drive, Miami, FL

1233133, USA

13

$14{ }^{\mathrm{b}}$ Fisheries Resource and Monitoring Division, Northwest Fisheries Science Center, National

15 Marine Fisheries Service, National Oceanic and Atmospheric Administration, 2032 S.E. OSU

16 Drive, Newport, OR 97365, USA

17

18

19

20

21

22

$23{ }^{1}$ Corresponding author (tel: +1 305.361.5761; e-mail: daniel.goethel@noaa.gov) 


\section{Abstract}

26 Misidentifying spatial population structure may result in harvest levels that are unable to achieve

27 management goals. We developed a spatially-explicit simulation model to determine how

28 biological reference points (BRPs) differ among common population structures, and to

29 investigate the performance of management quantities that were calculated assuming incorrect

30 spatial population dynamics. Simulated reference points were compared across a range of

31 population structures and connectivity scenarios demonstrating the influence of spatial

32 assumptions on management benchmarks. Simulations also illustrated that applying a harvest

33 level based on misdiagnosed spatial structure leads to biased stock status indicators,

34 overharvesting or foregone yield. Across the scenarios examined, incorrectly specifying the

35 connectivity dynamics (particularly misdiagnosing source-sink dynamics) was often more

36 detrimental than ignoring spatial structure altogether. However, when the true dynamics

37 exhibited spatial structure, incorrectly assuming panmictic structure resulted in severe depletion

38 if harvesting concentrated on more productive population units (instead of being homogenously

39 distributed). Incorporating spatially-generalized operating models, such as the one developed

40 here, into management strategy evaluations (MSEs) will help develop management procedures

41 that are more robust to spatial complexities.

43 Keywords: spatial population structure, biological reference points, maximum sustainable yield, overfishing, fisheries management, population dynamics, connectivity, stock assessment 


\section{Introduction}

48 Fish movement and dispersal stem from a variety of biotic and abiotic factors (Bowler and

49 Benton 2005) and contribute to a continuum of genetic variation and associated population

50 structures (Reiss et al. 2009; Ciannelli et al. 2013). Spatial connectivity is an important facet of

51 fish population dynamics that helps safeguard population units against natural and anthropogenic

52 perturbations and maintains population stability (Kerr et al. 2010a,b). The spatial distribution of

53 fishing effort can also influence population structure and displacement of effort has been used as

54 a management tool for implementing conservation strategies (e.g., implementing Marine

55 Protected Areas; Punt and Methot 2004; McGilliard et al. 2015). Protecting and conserving

56 spatial population structure has been a central concern for rational fisheries management for over

57 a century (Hjort 1914; Beverton and Holt 1957; Sinclair 1988; Cadrin and Secor 2009).

59 There has been increasing effort in recent decades to incorporate spatial heterogeneity in

60 population and fishery dynamics into stock assessment (and ecosystem) models that underlie

61 management advice (see review by Goethel et al. 2011), and to develop marine policies that

62 directly protect spatial population structure, including sub-population components (e.g.,

63 spawning populations; Kritzer and Liu 2014). However, spatial structure is rarely concurrently

64 and holistically evaluated across the entire assessment-management interface. The spatial scale

65 of stock assessment models is often limited by the available data, which, until recently, has

66 typically been reported by broad-scale management units (Wilen 2004). Consequently, the

67 ability to achieve the desired objectives of fine-scale fishery regulations is severely hampered by

68 using outputs of stock assessments that do not match the desired spatiotemporal scale (Cope and

69 Punt 2011; Goethel et al. 2016). 
71 Simulation experiments that evaluate spatial processes can be useful tools for understanding the

72 importance of spatial population structure for the sustainable management of marine resources

73 (e.g., Pelletier and Mahévas 2005; Kerr and Goethel 2014). In certain cases, it has been

74 demonstrated that spatially-aggregating data or assessment results across known spatial

75 components may be warranted or even statistically advantageous, particularly if there is little

76 genetic differentiation or sample sizes are limited (Li et al. 2015; Benson et al. 2015; Goethel et

77 al. 2015; Punt et al. 2015). However, the majority of spatial simulations have indicated that

78 ignoring spatial structure is likely to be detrimental either to the resource, the harvesters or both

79 (for reviews see Kerr and Goethel 2014 and Goethel et al. 2016).

81 When management (e.g., setting of catch quotas) ignores population structure or connectivity

82 among population units, there is increased potential for overharvesting and system productivity

83 is often incorrectly estimated (Fu and Fanning 2004; Kerr et al. 2014; de Moor and Butterworth

84 2015). Even when population structure is recognized and accounted for within the management

85 framework, if the spatial dynamics of the fishery (e.g., gear selectivity or effort) are ignored, the

86 possibility of overharvesting can remain (Fahrig 1993; Mchich et al. 2006; Ling and Milner-

87 Gulland 2008; Benson et al. 2015; Hoshino et al. 2014). Concomitantly, underharvesting can

88 also occur when effort is not efficiently allocated between spatial units, resulting in foregone

89 yield and lower net revenue for fishing fleets (Tuck and Possingham 1994). Because harvest

90 strategies are often context-dependent, no single, optimal approach to distributing fishing effort

91 exists when spatial structure is present (Steneck and Wilson 2010). For instance, the optimal

92 strategy when source-sink dynamics are modeled has been shown to differ between focusing 
93 harvest on the source or the sink population, exclusively, depending on modeling assumptions

94 and management objectives (Tuck and Possingham 1994; Sanchirico and Wilen 2001, 2005;

95 Wilberg et al. 2008).

97 Spatial dynamics can complicate the determination of management benchmarks, because of the

98 multi-level spatiotemporal interactions that occur among individual fishermen behavior

99 (targeting), differences in gear selectivity among fleets, regulatory management, and the

100 underlying population demographics (Steneck and Wilson 2010; Goethel et al. 2016; Thorson et

101 al. 2016, this issue). Surplus production models have been used to estimate maximum

102 sustainable yield (MSY) when metapopulation dynamics exist and sub-populations are linked

103 through movement or recruitment dynamics (Carruthers et al. 2011; Takashina and Mougi 2015).

104 For instance, using a metapopulation operating model, Ying et al. (2011) demonstrated that

105 ignoring metapopulation structure led to localized depletion, because biased stock status

106 indicators were estimated from spatially-aggregated surplus production models. Yield-per-

107 recruit (YPR) and spawner-per-recruit (SPR) models have also been adapted to account for

108 spatial structure within a population by allowing movement among population patches (e.g.,

109 Beverton and Holt 1957; Punt and Cui 2000) or by addressing heterogeneity in effort and

110 population distribution using individual-based models for sessile species (Hart 2001, 2003;

111 Truesdell et al. 2016). When stock-recruitment dynamics are accounted for directly, slightly

112 more complex simulation models can be utilized to calculate a suite of potential spatially-explicit

113 reference points. For example, Kerr et al. (2014) illustrated how accounting for population

114 structure and genetic straying (i.e., connectivity among spawning components) in Gulf of Maine 
115 cod could lead to different interpretations of population productivity and system yield compared

116 to spatially-aggregated models.

118 However, there are few instances of integrated assessment-management frameworks that

119 incorporate spatial structure into both the stock assessment model and the resulting simulations

120 of management benchmarks or yield projections. For tuna in the western and central Pacific

121 Ocean, the MULTIFAN-CL software program (Fournier et al. 1998; Hampton and Fournier et al.

122 2001) is used to provide spatially-explicit estimates of exploitation by modeling catch by region

123 and allowing connectivity among regions. In many applications, a single interbreeding

124 population is modeled allowing equilibrium yield or depletion (relative to unfished levels) based

125 reference points to be defined for the entire population (or system) without a mismatch in spatial

126 structure. However, recent modeling additions allow performing these analyses regionally,

127 thereby preserving the same connectivity and fishery dynamics utilized in the assessment model

128 (J. Hampton, SPC, Nouméa, New Caledonia, personal communication, 2016). Similarly,

129 assessment of the snapper resource in New Zealand is undertaken utilizing a spatially-explicit

130 model (i.e., a customized version of the CASAL software program; Bull et al. 2012) to

131 simultaneously model the three populations in the SNA1 management unit (Francis and

132 McKenzie 2015). This model assumes that each population exhibits natal fidelity (i.e., natal

133 homing) and connectivity is incorporated by calculating the degree of spatial overlap within each

134 geographic zone, while allowing individuals to perform instantaneous spawning migrations to

135 their natal population's spawning area. Population-specific virgin biomass $\left(\mathrm{B}_{0}\right)$ estimates are

136 utilized in conjunction with deterministic $\mathrm{B}_{\mathrm{MSY}}$ simulations to determine stock status, which

137 explicitly accounts for connectivity dynamics and provides reference points both by geographic 
138 area and by population unit. Although SNA1 snapper provides one of the few examples of a

139 complete spatially-explicit assessment-management framework, many uncertainties exist

140 particularly regarding population structure and connectivity assumptions (Francis and McKenzie $1412015)$.

142

143 Despite increasing awareness that fishery and population spatial structure have important

144 implications for defining management benchmarks and resulting harvest levels, investigations

145 have often been focused on a single application involving only one or two assumed population

146 structures. We develop a spatially-explicit simulation framework that can account for a variety

147 of spatial processes, then apply it across a relatively comprehensive range of common spatial

148 population structures and connectivity dynamics to provide a broad comparison of resulting

149 biological reference points. Next, we demonstrate the management implications of

150 misdiagnosing population structure by exploring the potential for overharvest and loss of yield

151 when harvest levels are applied based on incorrect management benchmarks. By improving our

152 understanding of the consequences associated with misidentifying population structure at the

153 assessment-management interface (e.g., the conversion of assessment outputs into management

154 advice), resource managers will be better able to identify potential harvest policy pitfalls and

155 prioritize limited management resources (e.g., to determine the cost/benefit of fine-scale data

156 collection; Goethel et al. 2016).

\section{Methods}

159 A generalized simulation framework was built to utilize stock assessment input (e.g., life history 160 and demographics) and output values (e.g., terminal year abundance, natural mortality, fishery 
161 selectivity, and recruitment parameter estimates) in order to project resource dynamics assuming

162 a particular spatial population structure and associated connectivity dynamics. The purpose of

163 the framework was twofold: to determine reference points under a variety of assumed spatial

164 dynamics and to address the management implications of applying a harvest level developed

165 with misdiagnosed spatial dynamics (Figure 1).

166

\section{Generalized Simulation Model}

168 The age-structured population dynamics are described below, but for further details see Goethel

169 et al. (2011; Section 4). Each implementation of the model differs only in the assumed

170 population structure and connectivity dynamics. Table 1 provides a glossary defining important

171 terms used throughout the article.

172

173 The model was designed to perform simulations in two stages using both AD Model builder

174 (ADMB; Fournier et al. 2012) and Program R (R core team 2012) statistical computing software.

175 The first stage determined biological reference points (BRPs; Figure 1). Model inputs were used

176 to simulate population dynamics forward through time until equilibrium was reached. An

177 iterative search algorithm was implemented that ran the model across combinations of fishing

178 mortalities (according to a defined step size for each fleet and area) to find the desired BRP. In

179 the current study, $\mathrm{SSB}_{\mathrm{MSY}}$ (achieved by fishing at the harvest rate, $\mathrm{u}_{\mathrm{MSY}}$, that achieved the

180 maximum system yield) was used as a BRP for comparative purposes. However, the model

181 search algorithm could be setup to achieve any number of alternative depletion or yield-based

182 BRPs.

183 
184 The second stage determined the impact of fishing at alternative harvest levels (Figure 1).

185 Instead of using the search algorithm to find the desired BRP, a harvest rate (or yield) was

186 specified and the model dynamics were simulated forward using this value at the appropriate

187 scale (i.e., system-wide or area-specific values could be input). The primary function was to

188 investigate the impact of misdiagnosing spatial population dynamics by fishing at the harvest

189 rate that achieved the desired BRP in stage 1, but for an incorrectly assumed spatial structure

190 (i.e., the input harvest rate did not achieve the BRP for the true simulated population structure).

191 The Newton-Raphson method was utilized to iteratively tune the model until the fishing

192 mortality that corresponded to the desired harvest rate by area was approximated within a certain

193 error threshold. The default assumption when applying harvest rates was that fishing effort was

194 homogenously distributed across areas. When the applied harvest rate was for an assumed single

195 area population, but the true dynamics contained multiple areas, the harvest rate was evenly

196 applied to all areas. Other effort allocation assumptions could be applied across areas to

197 approximate concentration of fishing effort, while still being constrained to maintain the same

198 overall (i.e., system-wide) input harvest rate.

\section{Population Structure}

201 The population structure was defined by the number of population units, the interactions among

202 units, and the recruitment dynamics. Four types of population structure were considered

203 corresponding to the main types typically modeled in spatially-explicit stock assessments

204 (Goethel et al. 2011): panmictic, single population with spatial heterogeneity, multiple

205 populations with natal homing, and metapopulation structure (Figure 2A). When defining each

206 of these population structures, careful consideration of definitions is warranted, especially in the 
207 determination of geographic units versus population units. For the purposes of this study, an

208 'area' was defined as a geographic unit representing the spatial extent over which a homogenous

209 fishing mortality acted. Depending on the type of population structure, an area may contain a

210 segment of a single population, an entire population or segments of multiple populations. A

211 population was defined as a self-reproducing biological entity within which all fish were able to

212 reproductively mix resulting in a single spawning stock biomass (SSB) that determined

213 population-specific recruitment values based on a unique stock-recruit function. Depending on

214 the type of population structure, area and population may be synonymous or a population may be

215 scattered across multiple areas.

217 Panmictic structure was defined as a single reproductively mixing population where no spatial

218 structure existed (i.e., fish were well-mixed throughout the area). A unit population was

219 assumed such that all fish were homogenously distributed across a single area and no

220 immigration or emigration occurred. A single stock-recruit function was utilized with all mature

221 fish in the population contributing to the SSB. Panmictic structure represents the simplest

222 possible population structure and is one of the most common assumptions in stock assessment

223 models.

225 When spatial structure was assumed to occur within a single population, the resulting spatial 226 heterogeneity was modeled by allowing multiple areas within the population. A single stock-

227 recruit function was utilized with SSB summed across all areas. A single genetic population was 228 assumed to come from a single larval pool. Total abundance before movement, $N_{B E F}$, at the 229 youngest age, $a_{0}$, for a given population $(j)$ and year $(y)$ was a function (based on the stock- 
230 recruit relationship) of the total SSB summed across all areas (r), while the area-specific

231 abundance at the youngest age was the total abundance multiplied by the apportionment factor

$232(\xi)$ for that area:

$$
\begin{gathered}
N_{j, y, a_{0}, B E F}^{\sum r}=f\left(\sum_{a} S S B_{j, y, a}^{\sum r}\right) \\
N_{j, y, a_{0}, B E F}^{r}=\xi_{j}^{r} N_{j, y, a_{0}, B E F}^{\sum r}
\end{gathered}
$$

234 A wide variety of species exhibit some degree of spatial heterogeneity in distribution, despite

235 maintaining a single reproductive population (e.g., Gulf of Alaska sablefish; Hanselman et al.

236 2015).

237

238 Metapopulation structure was defined similarly to a single population with multiple areas, except

239 that multiple populations were modeled simultaneously. Reproductive mixing occurred among

240 populations, through the movement of mature individuals, but each population was assumed to

241 maintain its own larval pool. For metapopulation dynamics, area and population delineations

242 were now synonymous (i.e., $r=j$ ), because once a fish moved into another area it assumed the

243 reproductive dynamics and demographics of the population residing in that area. Basically, a

244 fish was instantaneously exposed to the dynamics of the population that inhabited the area that it

245 currently occupied, which assumed that environment was the main driver of life history (not

246 genetics). The recruitment dynamics followed Equation 1, but multiple populations were

247 modeled simultaneously each of which maintained its own stock-recruit function defined by the

248 SSB of all fish currently residing in the corresponding area. Metapopulation structure is

249 becoming a more widely observed form of population structure for marine fish, and is frequently 
250 detected in reef fish and small pelagics (e.g., Atlantic herring; Kritzer and Sale 2004; Kerr et al.

$2512010 b)$

252

253 Natal homing (also known as the overlap model; Porch 2003) was the most complex population

254 structure evaluated. Multiple populations were modeled, but no reproductive mixing occurred

255 among them. Similar to a metapopulation, each population unit maintained its own stock-recruit

256 relationship. However, fish only contributed to the SSB of their natal population. As individuals

257 moved among population areas, they cohabitated with fish of other natal populations but were

258 unable to reproduce with them. Because of the overlap of non-interbreeding populations within

259 an area, area was no longer equivalent to population (i.e., $r \neq j$ ). Once again, recruitment was

260 based on Equation 1. Contrary to metapopulation structure where recruitment was determined

261 from all the SSB in the given population area, natal homing implied that individuals not within

262 the confines of their natal population area could not reproduce unless they underwent a spawning

263 migration (see Equation 2 in the following section for a description of SSB calculations for

264 alternative natal homing scenarios). Demographics were now assumed to be defined by the natal

265 population (i.e., vital rates no longer changed as an individual moved among areas), which

266 implied that life history characteristics were determined by genetics (not environment). Natal

267 homing has been hypothesized for many large pelagics (e.g., Atlantic bluefin tuna; Rooker et al.

268 2008) and is a well-known trait for salmon.

270 Movement Parametrization

271 Simulated movement used the box-transfer method, which assumed a certain fraction of the

272 population instantaneously moved to the other areas at the beginning of the year. The movement 
273 parameter, $T_{j, y, a}^{r \rightarrow s}$, represented the fraction of fish from population $j$ in year $y$ at age $a$ that moved

274 from area $r$ to area $s$ (for the simulation scenarios presented here movement was time-invariant).

275 The population subscript changed to the new population area superscript (i.e., movement was a

276 Markovian process) for metapopulation structure, but not for natal homing (i.e., movement

277 characteristics were defined by the natal population). Age-specific movement was incorporated

278 by allowing different movement rates for the youngest age class compared to all other age

279 classes. The primary assumption was that if, for example, the model started at age-0 (i.e., the

280 stock-recruit function provided the number of age-0 eggs or larvae), then age-0 movement would

281 represent larval drift and would be characterized by different dynamics than the movement of

282 older fish. Additionally, it was assumed that apportionment of larvae and larval drift were

283 separate processes (i.e., age-0 larvae were apportioned to area, and then allowed to move among 284 areas).

286 Two unique movement scenarios were examined using the natal homing population structure.

287 Spawning migrations were incorporated by defining a probability of returning, $\operatorname{Pr}($ SpawnReturn),

288 as the fraction of the natal population not in the natal area that returned to spawn, and which was

289 assumed to occur instantaneously at the time of spawning. In this case, a fish could add to the

290 SSB of its natal population, despite residing in a non-natal area (i.e., as a result of the

291 instantaneous spawning migration):

$$
\begin{gathered}
N_{j, y, a_{0}, B E F}^{r=j}=f\left[\sum_{a} S S B_{j, y, a}^{r=j}+\sum_{r, r \neq j}\left(\operatorname{Pr}(\text { SpawnReturn })_{j}^{r} * \sum_{a} S S B_{j, y, a}^{r \neq j}\right)\right] \\
N_{j, y, a_{0}, B E F}^{r \neq j}=0
\end{gathered}
$$


293 By accounting for fish that did not contribute to SSB, the spawning migration probability

294 effectively allowed for skipped spawning (i.e., mass resorption of oocytes), which has been

295 observed in some species that demonstrate natal homing (e.g., Atlantic cod and bluefin tuna;

296 Rideout and Tomkiewicz 2011).

298 The second movement scenario (termed natal return; Table 1) was defined to approximate

299 ontogenetic movement. Movement was allowed at the initial age (i.e., larval drift). A permanent

300 return migration to the natal area could then occur at a certain age, $a_{R E T}$, with a probability given

301 by $\operatorname{Pr}($ PermReturn). Movement was not allowed at any other ages. Recruitment was thus a

302 function of the SSB in the natal population area plus the corresponding SSB of fish that moved

303 back to the natal population at $a_{R E T}$ :

$$
N_{j, y, a_{0}, B E F}^{r=j}=f\left[\sum_{a} S S B_{j, y, a}^{r=j}+\sum_{r, r \neq j}\left(\operatorname{Pr}(\text { PermReturn })_{j}^{r} * S S B_{j, y, a=a_{R E T}}^{r \neq j}\right)\right]
$$

305 With this scenario, fish that did not return (according to $a_{R E T}$ ) never contributed to the SSB. This 306 configuration was meant to approximate an ontogenetic migration back to the natal population 307 once a fish had reached maturity. The basic ecological premise was that larval or young-of-the308 year fish settled and spent their juvenile stage in various areas (e.g., nursery grounds) where they 309 did not contribute to the SSB. Then, once maturity was reached, adult fish would move back to

310 the natal population and contribute to SSB (assuming negligible straying). Ontogenetic

311 migrations have been observed in a number of species (e.g., Gulf of Alaska sablefish; Hanselman

312 et al., 2015), and has been hypothesized in conjunction with natal homing for some large

313 pelagics (e.g., Atlantic bluefin tuna; Rooker et al. 2008). Although the implemented natal return 
314 scenario does not explicitly match any known ontogenetic migration patterns, it represents a first

315 approximation to the more complex versions seen in the real world.

\section{Population Dynamics}

318 Abundance was projected forward from input initial abundance-at-age and calculated recruitment

319 at the minimum age (Figure 2B). Recruitment calculations assumed a Beverton-Holt stock-

320 recruit model, where SSB was calculated based on weight and was adjusted based on the

321 assumed population structure and movement dynamics (as described above) and for the time of

322 spawning. Mortality was assumed to be a function of area. Fishing mortality was separated into

323 an area- and fleet-specific yearly multiplier, $F$, and an age-specific selectivity component.

324 Selectivity, $v$, for each of the modeled fleets, $f$, was input directly by age. Any number of fleets

325 was allowed within each area (for the simulation scenarios presented here only one fleet per area

326 was modeled). Natural mortality, $M$, was input directly and could vary by age, year, and area. In

327 the recruitment year, mortality was discounted for the fraction of the year that fish underwent

328 mortality based on the time of spawning (and hence birthdate). Abundance-at-age at the

329 beginning of the year before movement, $N_{B E F}$, in area $r$ from natal population $j$ in year $y$ and at

330 age $a$ was calculated from the abundance after movement, $N_{A F T}$, in the previous year and age as:

$$
\begin{gathered}
N_{j, y, a, B E F}^{r}=N_{j, y-1, a-1, A F T}^{r} e^{\left[-\left(F_{j, y-1, a-1}^{r, \sum f}+M_{j, y-1, a-1}^{r}\right)\right]} \\
F_{j, y-1, a-1}^{r, \sum f}=\sum_{f} v_{j, y-1, a-1}^{r, f} F_{j, y-1}^{r, f}
\end{gathered}
$$

332 The terminal age was assumed to be a plus group that was the summation of all fish that survived

333 to the plus group age from the previous age along with all fish already in the plus group that 
334 survived to the next year. Instantaneous movement immediately followed at the start of the year,

335 and abundance-at-age after movement, $N_{A F T}$, was:

$$
N_{j, y, a, A F T}^{r}=\sum_{s} T_{j, y, a}^{s \rightarrow r} N_{j, y, a, B E F}^{s}
$$

337 Catch-at-age, $C_{a}$, was calculated using Baranov's catch equation based on the area- and fleet338 specific mortality and selectivity values and the available abundance after movement, while 339 yield, $Y$, was the summation over age of catch-at-age multiplied by the weight-at-age, $w$ :

$$
\begin{gathered}
C_{j, y, a}^{r, f}=N_{j, y, a, A F T}^{r}\left(1-e^{\left[-\left(F_{j, y, a}^{r, \sum f}+M_{j, y, a}^{r}\right)\right]}\right) \frac{v_{j, y, a}^{r, f} F_{j, y}^{r, f}}{F_{j, y, a}^{r, \sum f}+M_{j, y, a}^{r}} \\
Y_{j, y}^{s, r, f}=\sum_{a}\left(C_{j, y, a}^{r, f} * w_{j, y, a}\right)
\end{gathered}
$$

341 The general spatial and spatiotemporal dynamics are illustrated in Figures 2A and 2B.

\section{Model Outputs}

344 Several output quantities that are typically important for making management decisions were

345 provided for each year of the simulation and at all spatial scales (i.e., system-wide or by area).

346 By providing results at different spatial scales, the impacts of applying a given mortality rate

347 could be examined at different levels, which can be particularly useful when comparing different

348 types of assumed population structures. Results were also provided by area and by natal

349 population in order to allow comparison among different population structures. Biological

350 metrics included: abundance-at-age, recruitment, biomass, SSB, depletion

351 (biomass Current $_{\text {biomass }}$ Initial), and spawning potential ratio ( $\mathrm{SPR}=\mathrm{SSB}_{\text {Current }} / \mathrm{SSB}_{0}$, where $\mathrm{SSB}_{0}$ 
352 was calculated based on unfished equilibrium SSB and the parameters of the stock-recruit curve).

353 Mortality-based metrics included: catch-at-age, yield, and harvest rate or exploitation fraction

354 (yield/biomass).

Model Application

357 The generalized framework was applied to evaluate three main study objectives using MSY-

358 based reference points. MSY-based reference points were chosen for illustrative purposes,

359 because they are widely used (as explicit or proxy reference points) and discussed in fisheries

360 management. However, their use is not meant to represent the basis for any particular real-world

361 harvest policy. For the first objective $\left(B R P \_D e v\right)$, the stage 1 model (Figure 1) was run for

362 several alternative spatial population structures and various connectivity dynamics, and the

363 resulting MSY-based reference points were compared. The second objective $\left(H L \_A p p\right)$ applied

364 results from the stage 1 model runs to the stage 2 model (Figure 1), where an MSY-based harvest

365 level was applied based on an incorrect assumption regarding spatial structure and connectivity

366 dynamics. Thus, the dynamics of the true population structure were simulated using the harvest

367 rate that achieved MSY for the assumed population structure. Model outputs (e.g., level of

368 depletion, foregone yield, and bias in stock status indicators) were then compared across

369 scenarios. The simulation model for objectives one $\left(B R P_{-}\right.$Dev $)$and two $\left(H L_{-}\right.$App $)$was

370 conditioned to loosely emulate a mid-water pelagic, hake-like species with many of the life

371 history characteristics borrowed from the Pacific hake (Merluccius productus) stock assessment

372 (Grandin et al. 2016). This species was chosen to provide realistic parameters to initialize the

373 model (see Table 2 for input values), but, given the many simplifying assumptions made, the

374 results were not meant to be representative for any particular species and thus were not suitable 
375 as the basis for management advice. The third objective (Snapper_App) was to apply the

376 generalized simulation framework (stages 1 and 2) to a species with alternative life history

377 parameters and to explore the impact of spatial effort allocation. The input parameters, spatial

378 population structure, and connectivity scenarios were based on aspects of Gulf of Mexico red

379 snapper (Lutjanus campechanus), though model evaluations are exploratory and not suitable as

380 the basis for management advice.

382 Base Dynamics and Scenarios: Mid-water Pelagic

383 The simulation model used to evaluate objectives one (BRP_Dev) and two $\left(H L_{-} A p p\right)$ was first

384 parameterized by a base set of population dynamics and then adjusted to evaluate alternative

385 spatial structure and connectivity scenarios. The base model assumed 15 ages and deterministic

386 simulations were carried out for 200 years, a time period meant to allow equilibrium conditions

387 to occur. The initial age-structure was setup so that abundance at the youngest age class was

388 equivalent to $R_{0}$ (virgin recruitment; 3.125 million fish), and the abundance-at-age was at

389 unfished equilibrium assuming an age-invariant natural mortality of 0.226 , but adjusted such that

390 the total SSB was equivalent to $S S B_{0}$ (virgin spawning stock biomass; 2.397 million mt). A

391 Beverton-Holt stock-recruit function was assumed with a steepness of 0.814 , and no stock-recruit

392 deviations were incorporated. SSB was in weight and weight-at-age was input in kilograms. A

393 single fleet was assumed for each area and selectivity was set equivalent to maturity in order to

394 avoid any influence of differences in these quantities on results. All parameters were time-

395 invariant (see Table 2 for input parameter values). 
397 For population structures assuming multiple areas, the number of areas was two for tractability

398 and ease of interpretation of results. The vital rates were assumed constant across all areas or

399 populations and $R_{0}, S S B_{0}$, and initial abundance-at-age were evenly apportioned among

400 populations in order to ensure that results were not influenced by differential population

401 demographics and that differences in spatial dynamics were the axis of evaluation. For scenarios

402 where differential recruitment apportionment or productivity among areas was assumed, the first

403 area had the potential to produce up to $30 \%$ of the total recruitment, while the second area could

404 produce up to $70 \%$. For a single population with multiple areas, this was accomplished by

405 splitting the recruitment apportionment factor 30/70 (instead of the base 50/50 split). For

406 multiple population scenarios, the split was achieved by scaling the population-specific $R_{0}$ and

407 associated $S S B_{0}$, which then also required rescaling the initial abundances-at-age.

408

409 Movement rates and types differed according to objective and scenario set. Movement was

410 separated between larval drift (constant movement at age $a_{0}$ ) and adult movement (constant

411 movement for ages greater than $a_{0}$ ). Two levels of movement were evaluated (high or low

412 residency) along with two types of movement (bidirectional or unidirectional), and both could

413 occur at the larval or adult stage. Bidirectional movement allowed fish to move between both

414 areas, while unidirectional movement represented source-sink dynamics (i.e., fish move in one

415 direction). For bidirectional movement, high residency indicated that $80 \%$ of fish stayed in area

4161 and $85 \%$ stayed in area 2 in any given year, while low residency indicated that $60 \%$ stayed in

417 area 1 and $65 \%$ stayed in area 2. For unidirectional movement, fish were only allowed to move

418 from area 2 to area 1 (representing movement from the more productive area to the less

419 productive area when productivity differed) with high residency set to $85 \%$ and low residency to 
$42065 \%$. For natal homing scenarios, spawning migrations and natal return were considered. The

421 probability of return was $75 \%$ for spawning migrations and constant across population areas,

422 which represented a plausible level given recent literature on skipped spawning (Rideout and

423 Tomkiewicz 2011). For the natal return models, high and low return probabilities $(85 \%$ or $65 \%$,

424 respectively) were evaluated, where the age of return was set to age-4 (roughly corresponding to

$42575 \%$ maturity). Alternative movement levels were chosen to provide a reasonable range of

426 plausible rates but, again, were not meant to reflect any particular species.

428 Scenarios for the first objective $\left(B R P_{-}\right.$Dev) were developed to calculate and compare reference

429 points across different spatial structures and connectivity assumptions. The first subset of

430 scenarios focused on the role of adult movement (Adult_Move; a complete listing is provided in

431 Supplementary Material Table S1). The second subset looked at the impact of larval

432 connectivity (Larval_Move; Supplementary Material Table S2). The third subset allowed both

433 adult and larval connectivity (All_Move; Supplementary Material Table S3). The fourth subset

434 demonstrated the impact of full connectivity dynamics along with variation in recruitment (i.e.,

435 productivity) across areas (Move+Prod; Table 3).

437 Scenarios for the second objective $\left(H H_{-}\right.$App $)$were developed using model output harvest levels 438 from the high adult and high larval residency scenarios of objective one, subset four

439 (Move+Prod), as these represented the most inclusive set of MSY-based harvest levels

440 examined. For each scenario, there was a true underlying spatial structure that determined the

441 dynamics of the system and an assumed spatial structure that was used to guide management

442 (i.e., the implemented harvest level) for the true system. The applied harvest rate was that which 
443 maximized yield ( $\left.\mathrm{u}_{\mathrm{MSY}}\right)$ for the assumed spatial structure. For situations where the assumed

444 spatial structure was panmictic, the panmictic $\mathrm{u}_{\mathrm{MSY}}$ was applied to each of the areas in the true

445 population structure. On the other hand, when multiple areas were assumed but the true structure

446 was panmictic, the system-wide $\mathrm{u}_{\mathrm{MSY}}$ from the assumed structure (i.e., the total $\mathrm{u}_{\mathrm{MSY}}$ across all

447 areas) was used as the harvest rate for the panmictic population. When multiple area spatial

448 structures were examined for both the assumed and true dynamics, the assumed $\mathrm{u}_{\mathrm{MSY}}$ for the first

449 [second] area was applied to the first [second] area in the true dynamics. Resulting area-specific

450 and system-wide terminal year outputs (e.g., SSB, yield, and SPR) allowed comparison of how

451 misdiagnosing spatial structure and unknowingly implementing inappropriate management

452 harvest levels may affect the ability to achieve long-term management goals.

454 Base Dynamics and Scenarios: Red Snapper-like

455 The simulation model used to evaluate objective three (Snapper_App) was also parameterized by

456 a base set of population dynamics (Supplemental Table S4), but some simplifying assumptions

457 were made compared to the current assessment (e.g., only a single fleet per area was modeled

458 here). Reference points were evaluated based on various hypothesized spatial structure and

459 connectivity scenarios. For red snapper, spatial structure is known to exist, but the causes and

460 levels of potential mixing among areas is not well known (Patterson 2007; Karnauskas et al.

461 2013). The current stock structure applied to the assessment of red snapper is essentially two

462 populations (eastern and western Gulf of Mexico) with management treating them as a single

463 population, but tagging studies and larval drift models indicate that metapopulation structure

464 may exist (Patterson 2007; Karnauskas et al. 2013). 
466 Life history parameters were derived from the most recent stock assessment (SEDAR 2015), but

467 some parameters were altered to fit the various modeling assumptions. All parameters were

468 assumed constant across areas (as was done in the stock assessment) and were time-invariant.

469 Selectivity was taken from the dominant fishery (the recreational fleet in the eastern area) in

470 order to avoid the added complexity of averaging selectivity across fleets when a single

471 panmictic population was assumed. The assessment fixes steepness at 1.0, but allows a time-

472 varying recruitment distribution parameter in order to accommodate the independent recruitment

473 that is thought to exist between the eastern and western populations. For this study, steepness

474 was fixed at 0.85 in order to maintain the reliance of recruitment on SSB. When evaluating a

475 single population with two areas, the recruits were apportioned using the time-averaged

476 apportionment factor estimated from the stock assessment (66\% of recruits are apportioned to the

477 western area, referred to as area 2 here). When evaluating metapopulation models, $R_{0}$ was

478 apportioned using the same ratio.

480 Three types of population structure were investigated based on previously hypothesized 481 connectivity dynamics (Patterson 2007): panmictic, a single population with two areas, and 482 metapopulation structure. For the two spatial population structures, different connectivity 483 dynamics were investigated based on larval connectivity hypothesized from a larval individual484 based model (IBM) developed for red snapper (Karnauskas et al. 2013). Five movement 485 scenarios were considered: no movement; bidirectional larval movement with average values 486 from the larval IBM ( $\sim 97 \%$ residency for each population); unidirectional larval movement at 487 maximum values from the larval IBM (the eastern, area 1, or western, area 2, is treated as a 488 source with residency of 93\%); unidirectional larval movement based on hypothesized maximum 
489 values (the eastern, area 1, or western, area 2, is treated as a source with residency of $80 \%$ ); and 490 bidirectional average larval movement (97\% residency) with bidirectional adult movement based 491 on hypothesized movement rates ( $90 \%$ adult residency for each population).

493 Associated reference points were developed for each population structure (see Table S5 for a list 494 of scenarios), and then MSY-based harvest levels were applied to investigate the impact of 495 misdiagnosing spatial structure when effort was apportioned evenly among areas

496 (Snapper_Even_Eff; see supplemental Figure S14 for specific scenarios). Uneven apportionment 497 of effort was also evaluated when panmictic stock structure was assumed (Snapper_Uneven_Eff; 498 see Figure 7 for specific scenarios), such that the input harvest rate on the eastern population 499 (area 1) was halved and the harvest rate on the western population (area 2) was increased until 500 the panmictic $\mathrm{u}_{\mathrm{MSY}}$ was achieved for the entire complex. The Snapper_Uneven_Eff scenarios 501 illustrated the detriments of ignoring population structure when management failed to limit 502 harvesting aggregation, and were meant to touch upon the potential impact that spatial fleet 503 dynamics (and lack of sub-population catch allocations) might have on naïve management 504 strategies.

506 Graphical Analysis

507 For all scenarios, model output comparisons were carried out through graphical analysis of 508 important management quantities (e.g., MSY, $\mathrm{SSB}_{\mathrm{MSY}}$, and $\mathrm{u}_{\mathrm{MSY}}$ ). When evaluating the impact 509 of misdiagnosing spatial population structure, results were presented as the ratio of the terminal 510 yield or SSB compared to either the true MSY or $\mathrm{SSB}_{\mathrm{MSY}}$ or the assumed MSY or $\mathrm{SSB}_{\mathrm{MSY}}$.

511 Yield comparisons provided an indication foregone yield, while SSB comparisons indicated the 
512 level of depletion and bias in a common stock status indicator (i.e., when compared to the true 513 stock status).

\section{Results}

516 Development of $B R P s\left(B R P \_D e v\right)$

517 Spatial population structure had important implications for resulting spatially-explicit 518 management harvest levels and biological reference points (Move+Prod scenario results are 519 described here and qualitatively summarized in Table 4; Adult_Move, Larval_Move, and 520 All_Move scenario results are shown in Supplemental Figures S1, S2, and S3, respectively).

521 Although system-wide (total) $\mathrm{u}_{\mathrm{MSY}}$ was relatively constant across population structures and 522 connectivity dynamics (with the exception of a few cases), resulting SSB $_{\text {MSY }}$ varied considerably 523 across scenarios (Table 4, Figure 3). In addition, different area-specific harvest rates were 524 required to maximize utilization across population structures (Figure 3). For instance, when 525 source-sink dynamics were present, the source population remained relatively unfished $\left(\mathrm{u}_{\mathrm{MSY}}\right.$ 526 was less than 0.05$)$, whereas the sink population was fished much harder ( $\mathrm{u}_{\mathrm{MSY}}$ was near 0.4$)$.

527 These results held for both metapopulation and single population, two area scenarios, but were 528 less pronounced (area-specific $\mathrm{u}_{\mathrm{MSY}}$ ranged from 0.15 to 0.23 ) for the natal homing scenarios 529 (Figure 3). The resulting system-wide $\mathrm{SSB}_{\mathrm{MSY}}$ was the lowest for the source-sink 530 metapopulation dynamics, due to the constant loss of SSB (and consequent recruitment) from the

531 source population. Adult connectivity was a more important factor than larval connectivity in 532 driving the lower $\mathrm{SSB}_{\mathrm{MSY}}$ for source-sink dynamics (scenarios 13 and 15 versus 12 and 14 in

533 Figure 3), because losses due to movement occurred at every adult age instead of just the

534 youngest age of the cohort (i.e., when only larval connectivity was considered). 
536 Similarly, differential recruitment exacerbated the relative differences in management quantities

537 across areas. Because fish always added to the SSB of their current resident area for the non-

538 natal homing scenarios, it was intuitive that the area receiving a subsidy (i.e., the sink) would be

539 able to sustain a higher fishing pressure. Interestingly, the results for bidirectional movement

540 began to mimic source-sink dynamics when productivity differed among populations (e.g.,

541 scenarios 17 and 19, Figure 3). When there was a metapopulation with bidirectional movement

542 and differential productivity, the more productive population needed to be protected, while

543 harvest on the less productive population could be much higher. However, with bidirectional

544 movement the loss of individuals to the less productive population could be offset by

545 immigration from the de facto sink population (i.e., $\mathrm{SSB}_{\mathrm{MSY}}$ was higher than for the true source546 sink scenarios).

548 For natal homing scenarios, system-wide SSB tended to be lower, but fluctuations in area549 specific harvesting rates (range of $0.15-0.25$ ) were not as strong as for metapopulation structure 550 (range of 0.05-0.45; Figure 3). When no spawning migrations were assumed to occur with 551 unidirectional movement, system-wide $\mathrm{SSB}_{\mathrm{MSY}}$ and associated $\mathrm{u}_{\mathrm{MSY}}$ declined by about $15 \%$

552 resulting in a 5\% decline in MSY compared to the same scenarios with spawning migrations.

553 These results were more pronounced for bidirectional movement (declines around 25\% for

$554 \mathrm{SSB}_{\mathrm{MSY}}$ and $\mathrm{u}_{\mathrm{MSY}}$ with a $10 \%$ reduction in MSY). Because fewer fish moved under source-sink 555 dynamics than with bidirectional movement, it was not surprising that $\mathrm{SSB}_{\mathrm{MSY}}$ was lower for the 556 latter because more fish resided outside their natal area and contributed less to natal SSB. 
559 The risk of depleting certain areas (within or among populations) while underutilizing others

560 differed across the scenarios examined, but tended to be greatest when the true population

561 structure involved metapopulation dynamics (results are qualitatively summarized in Table 5).

562 Ignoring spatial population structure (i.e., assuming panmictic structure) was not as detrimental

563 as might otherwise be expected for system-wide status (in terms of terminal SSB compared to

564 the true $\mathrm{SSB}_{\mathrm{MSY}}$ ), but it could lead to significant depletion of individual areas (Figure 4; Table

565 5). When the underlying dynamics involved source-sink connectivity, assuming no spatial

566 structure led to the source area being severely overharvested (SSB less than $40 \%$ of SSBMSY for

567 metapopulation structure) with the sink area being underharvested (SSB over $150 \%$ of SSB $\mathrm{MSY}_{\mathrm{M}}$

568 for metapopulation structure). Moreover, for metapopulation structure with source-sink

569 dynamics a $25 \%$ loss of yield resulted due to misdiagnosing stock structure (Supplemental

570 Figure S5). The main problem with assuming no structure was that managers would only be

571 provided stock status on a system-wide basis, which could indicate that the system was doing

572 well regardless of area-specific depletion (Figure 4 and Supplemental Figure S4).

573

574 Interestingly, assuming metapopulation structure when it was not occurring or simply

575 misdiagnosing the connectivity dynamics when metapopulation dynamics were correctly

576 assumed, resulted in the most frequent occurrence of depleting an area (Figure 5; Table 5).

577 When metapopulation structure with source-sink dynamics were assumed, the first area was

578 consistently depleted to low levels (SSB ranged from 15 to $50 \%$ of $\mathrm{SSB}_{\mathrm{MSY}}$ ), while the second

579 area was underfished (SSB was $120-140 \%$ of $\mathrm{SSB}_{\mathrm{MSY}}$ ) regardless of the true spatial structure.

580 The system-wide SSB tended to be maintained around the true $\mathrm{SSB}_{\mathrm{MSY}}$, a notable exception 
581 being for a single population with two areas and unidirectional movement (terminal SSB was at $58260 \%$ of $\mathrm{SSB}_{\mathrm{MSY}}$ ). The biggest detriment occurred for area 1 (i.e., SSB around $15 \%$ of $\mathrm{SSB}_{\mathrm{MSY}}$ )

583 when the true spatial structure involved natal homing. When metapopulation structure with

584 bidirectional movement was assumed, the implications were not as severe (minimum area-

585 specific $\mathrm{SSB}$ around $50 \%$ of $\mathrm{SSB}_{\mathrm{MSY}}$ ). In certain situations when metapopulation structure was

586 assumed, especially when the true spatial structure involved natal homing, there was

587 considerable foregone yield (5-25\%; Supplemental Figure S10).

589 The risk associated with assuming natal homing when in fact it was not occurring was relatively

590 low in most cases. Overharvesting an area by more than $10 \%$ occurred in only four scenarios

591 (Figure 6, Table 5), while there was mostly little foregone yield (Supplemental Figure S12). The

592 largest impacts were seen when the true underlying structure involved source-sink dynamics

593 (SSB in area 2 was around $30-70 \%$ of $\mathrm{SSB}_{\mathrm{MSY}}$ for metapopulation or single population, two area

594 true structure), though this result was pronounced for all true metapopulation structures

595 examined regardless of assumed natal homing movement dynamics. Misdiagnosing connectivity

596 dynamics when natal homing was correctly assumed had limited negative impact.

598 Red Snapper-like Application (Snapper_App)

599 Given the relatively limited level of larval and adult movement examined (Table S5), it was not

600 surprising that the system-wide reference points only differed slightly (Supplemental Figure

601 S13). Misdiagnosing spatial structure had limited impact on the resource (area-specific terminal

$602 \mathrm{SSB}$ was within $85 \%$ of true $\mathrm{SSB}_{\mathrm{MSY}}$ for all scenarios tested; Supplemental Figure S14) when

603 effort was evenly allocated (Snapper_Even_Eff scenarios). However, when panmictic structure 
604 was assumed and harvest effort was allowed to aggregate on the more productive area

605 (Snapper_Uneven_Eff scenarios), the potential for overharvesting increased drastically (system-

606 wide SSB was 75-90\% of $\mathrm{SSB}_{\mathrm{MSY}}$ for all scenarios tested; Figure 7). The western area (area 2)

607 was often depleted with the terminal SSB usually dropping to less than $50 \%$ of SSB $\mathrm{SSY}_{\text {and a }}$

608 minimum value around 15\%. However, the eastern area (area 1) was consistently well above its

$609 \mathrm{SSB}_{\mathrm{MSY}}$ (ranging from $125-200 \%$ of $\mathrm{SSB}_{\mathrm{MSY}}$ ). For most of the true population structures

610 examined, there was around a $25 \%$ loss in yield from the system when spatial structure was

611 disregarded and effort was not homogenously distributed (Supplemental Figure S15).

612

\section{Discussion}

614 Over the last three decades, there has been increasing awareness that spatial population structure 615 is an important facet of resilience for marine species (e.g., Sinclair 1988; Pelletier and Mahévas

616 2005; Kerr et al. 2010a,b; Ciannelli et al. 2013). However, little research has been devoted to

617 describing how ignorance of spatial dynamics may impact biological reference points or the

618 reliability of management strategies (e.g., Ying et al. 2011; Hoshino et al. 2014). Our results

619 demonstrate that management benchmarks and the harvest levels required to attain them are

620 strongly influenced by the underlying population structure and connectivity dynamics. For

621 instance, with metapopulation structure, system-wide harvest rates could be maintained at higher

622 levels compared to other population structures, particularly when source-sink dynamics were

623 present, because movement did not hinder reproduction and area-specific fishing mortality

624 occurred only on a single population at any given time. Yet, it is important to carefully monitor

625 area-specific harvest rates in order to avoid overharvesting more productive units, which

626 generally act to maintain resource abundance. Alternatively, for natal homing, harvesting within 
627 a given area occurs on multiple populations with different productivities so obtaining MSY-

628 based BRPs necessitated moderate harvest rates in all areas. Unlike with metapopulation

629 structure, area-specific harvest rates were generally independent of movement types and were

630 relatively constant across areas for natal homing scenarios.

631

632 Previous studies have suggested that ignoring spatial structure can lead to overharvesting and

633 localized depletion of sub-population components (e.g., Fu and Fanning 2004; Ying et al. 2011;

634 Hoshino et al. 2014). Our findings further support the general concept that ignoring spatial

635 structure and connectivity dynamics can lead to unintended consequences, and expands upon the 636 types of spatial scenarios for which that applies. For the set of spatial scenarios examined for

637 this study, systems that demonstrate source-sink dynamics have the highest potential to introduce 638 problematic management performance when spatial connectivity is not accurately understood.

639 Localized depletion was common when source-sink dynamics were misdiagnosed even though

640 the underlying population structure may be correct. Incorrect assumptions regarding

641 connectivity or mixing dynamics (even when spatial structure is properly defined) can lead to

642 similar, and sometimes worse, outcomes compared to incorrectly assuming no spatial structure

643 exists. This is problematic for stock assessment and resource management because connectivity

644 dynamics are rarely well understood (e.g., Porch et al. 1998; Goethel et al. 2015), yet there is no 645 good solution for dealing with this source of uncertainty in spatial population dynamics. Further

646 research on the integration of multiple models (e.g., ensemble modeling utilizing a variety of

647 plausible spatial hypotheses) into the stock assessment-management interface along with

648 explorations with spatially explicit management strategy evaluations should help improve 
649 understanding of the robustness of various management procedures to these and other

650 uncertainties.

652 It was somewhat surprising that when ignoring population structure (i.e., assuming a panmictic

653 population), a metapopulation with source-sink dynamics was the only true spatial structure

654 scenario that resulted in significant system-wide bias $(>20 \%)$ in terms of stock status and yield.

655 One important factor related to this finding was that assumed and true connectivity dynamics

656 only included high residency, low movement simulations for the $H L A P P$ scenarios. A

657 comparative analysis using low residency, high movement scenarios demonstrated more

658 pronounced impacts. The low movement scenarios were thought to provide a broader

659 representation of typical connectivity dynamics, but clearly the spectrum of results further

660 illustrates the importance of movement and population structure assumptions on the choice of

661 harvest strategies for marine resources.

662

663 A number of generalities and caveats exist with this work, and, to better understand the role of 664 these, further consideration and research is warranted. There were many area-specific factors 665 and assumptions (both within a single population and among populations) that could influence 666 results (e.g., degree of movement by age, size, area, and life stage, areal productivity, maturity, 667 growth, fishing effort allocation, and fleet selectivity). To keep the analysis tractable, many of 668 these factors, and the interactions among them, could not be explicitly investigated. The 669 assumed population and connectivity dynamics in the simulations conducted were reasonable, 670 yet simplified compared to real world applications. Additionally, as with most reference point 671 models, time-invariant model parameters were assumed during the deterministic projection 
672 period. Given the flexibility of the modeling approach, it is relatively straightforward to evaluate

673 alternative scenarios, allow for stochasticity in the projection period, and incorporate time-

674 varying parameters and seasonal time increments. Similarly, more complex connectivity

675 dynamics could be included (e.g., density-dependence and other functional forms). Further

676 research is needed that closely examines the interplay between specific connectivity assumptions

677 and the copious spatiotemporal biological, fleet, and management processes. By further

678 developing the general framework for new and alternate assumptions regarding spatial,

679 recruitment, and fishery dynamics, we expect that the basic understanding of how spatial

680 processes impact fisheries management will be continually refined.

682 There are many unresolved issues that remain with marine spatial assessment models that could 683 impact the reliability of simulation results. For instance, there is no best approach for dealing 684 with the issue of demographic changes of individuals as they move between areas (R. Methot, 685 NOAA NMFS, Silver Spring, MD, personal communication, 2016), which may only be tractable 686 with individual-based modeling approaches. A critical defining characteristic that separates natal 687 homing from metapopulation structure is the degree to which environment and genetics are 688 expected to determine a population's demographic rates and the rate at which an individual will 689 adapt to new environmental regimes. The basic theory of marine metapopulation dynamics 690 (Kritzer and Sale 2004) implies that a fish adheres to the demographics of the area that it moves 691 into (i.e., vital rates are essentially determined by the environment). Alternatively, natal homing 692 dynamics imply that a fish maintains its life history characteristics regardless of where it resides 693 (i.e., natal, via genetics or imprinting, demographics are upheld). In reality, both genetics and 694 environment influence demographic and vital rates to some degree and both modeling 
695 approaches have important limitations. When life history parameters differ by area, assuming

696 that a fish instantaneously adopts the demographics of a new area may result in a reduction in the

697 average size, weight or maturity of a fish as it moves throughout the spatial domain (i.e., rates

698 could be lower at older ages for different populations). Of course, assuming demographics are

699 purely genetic (as with natal homing) is also incomplete. Stock assessment software exists that

700 attempts to deal with these limitations by assigning vital rates to 'growth morphs' or 'platoons'

701 of fish that are assumed to have the same demographics (e.g., recruitment year-classes; Methot

702 and Wetzel 2013), but no fully satisfactory solution currently exists for spatial models.

703

704 Further, the instantaneous movement assumption continues to be an over-simplification in spatial

705 population models, because fish movement occurs across a continuum of physical, biological,

706 and chemical gradients (Turchin 1998). Miller and Andersen (2008) suggest that estimating

707 continuous time movement parameters (analogous to continuous fishing and natural mortality

708 rates) may be more appropriate for fisheries models. It might be worthwhile to test within the

709 current framework in order to illustrate the differences that result when fish are able to

710 continuously move from one mortality regime to another. However, until the causal mechanisms

711 that lead to continuous movement are better understood, it may be difficult to apply reference

712 points utilizing this assumption.

713

714 Developing more complex evaluations that include multi-component spatial dynamics like the

715 addition of differential selectivity, multiple fleets, and effort aggregation in areas of high

716 biomass concentration are appropriate next steps. The red snapper-like application with uneven

717 fishing effort demonstrated that as more complex, multi-component dynamics are included, the 
718 potential pitfalls of ignoring spatial structure could be magnified. Spatial heterogeneity exists in

719 both the distribution of fishery resources and fishing effort (Fahrig 1993; Guan et al. 2013), and

720 these are often not proportional to each other across space. Accounting for only the biological

721 aspects of spatial structure does not provide a complete overview of how spatial heterogeneity

722 can impact estimation of biological reference points and related harvest strategies. The snapper-

723 like results provide an indication of the increased complexities that result from spatial effort

724 dynamics, which supports the findings of Hoshino et al. (2014). A wide body of literature on

725 Marine Protected Areas (MPAs) has demonstrated the importance of spatial harvest

726 displacement for the determination of stock status indicators and achievement of conservation

727 goals (e.g., Punt and Methot 2004; Pincin and Wilberg 2012; McGilliard et al. 2015). Further

728 work is needed to identify and understand the combined impact of both biological connectivity

729 and spatial fleet dynamics (Fahrig 1993; McGilliard et al. 2015)

731 Our analysis represents a first step towards better understanding the role that population structure

732 has in defining management benchmarks and subsequent harvest levels. Despite the use of

733 simplifying assumptions, the modeling approach highlighted important patterns and

734 opportunities for investigation (i.e., types of spatial dynamics) that warrant further exploration.

735 Next steps include broadening the generalized simulation model to include increased complexity

736 in the spatiotemporal, population, and fishery dynamics and to more fully account for system

737 uncertainties. An evaluation of data requirements and the associated parameter bias/variance

738 tradeoff that must be confronted when moving to multi-dimensional spatial models, where

739 sample size can become limiting, would also be beneficial. Although the results of this work

740 provide a basic understanding of the interplay between complex spatial dynamics and estimates 
741 of management benchmarks for marine resources, we acknowledge that it only represents a first

742 step towards fully integrating spatial biological and fishery dynamics into fisheries policy. There

743 is a clear need for fisheries scientists and managers to be aware of spatial population structure,

744 because it can have strong implications for how to best manage a fishery to meet management

745 objectives (Fahrig 1993; Benson et al. 2015; Hoshino et al. 2014). In addition, spatial

746 heterogeneity due to fleet dynamics and regulatory measures (e.g., MPAs) only increases the

747 importance of accounting for spatial processes across the assessment-management interface

748 (Guan et al. 2013; McGilliard et al. 2015).

750 With the increasing recognition of the extensive interactions among time-varying spatial,

751 environmental, population, and fishery processes (Ciannelli et al. 2013), the reliance on static,

752 equilibrium models such as those traditionally used to calculate many biological reference points

753 should be reduced (Hilborn 2002; Hoshino et al. 2014). Developing management strategy

754 evaluations where the operating model is generalized to include many hypothesized spatial and

755 environmental complexities (similar to the model developed here) will allow testing the

756 robustness of management procedures to a variety of interacting dynamics, and will help

757 managers move away from harvest control rules based on BRPs developed with incomplete

758 assumptions (Butterworth and Punt 1999; Geromont and Butterworth 2015). Of particular

759 interest has been the exploration of empirically driven, spatially-explicit reference points that

760 could be used in lieu of or in tandem with conventional BRPs (Reuchlin-Hugenholtz et al. 2015,

761 2016). No matter how BRPs or harvest strategies are developed, it remains paramount that data

762 collection programs which elucidate migration pathways, connectivity dynamics, and

763 spatiotemporal population structure (e.g., genetic analyses, tagging data, larval transport, and 
764 fine-scale life history data) continue to be funded and expanded in order to support development

765 of more realistic spatial models that can help guide sustainable fisheries management.

766

767 Acknowledgements

768 Earlier versions of this manuscript were improved with reviews from Meaghan Bryan, Mandy

769 Karnauskas, Shannon Cass-Calay, Clay Porch, Owen Hamel, James Thorson, and 3 anonymous

770 reviewers. We would like to thank the organizers, Rick Methot and Mark Maunder, of the $7^{\text {th }}$

771 World Fisheries Congress (Busan, South Korea) theme session on "Advancements in Stock

772 Assessment and Provision of Management Advice" for allowing us to present these findings

773 along with all participants whose discussion on the topic helped improve our study. We also

774 thank Dana Hanselman, Amy Schueller, Brian Langseth, Jon Deroba, Pat Lynch, Terry Quinn, 775 and Steve Cadrin for helping to stimulate the ideas that led to this manuscript. Finally, we thank 776 the National Marine Fisheries Service Office of Science and Technology branch of NOAA for

777 providing funding under the Stock Assessment Analytical Methods (SAAM) project to support 778 this research.

779 


\section{References}

781 Benson, A.J., Cox, S.P., and Cleary, J.S. 2015. Evaluating the conservation risks of aggregate harvest management in a spatially-structured herring fishery. Fish. Res. 167: 101-113. doi: 10.1016/j.fishres.2015.02.003

Beverton, R.J.H., and Holt, S.J. 1957. On the dynamics of exploited fish populations. Fisheries Investment Series 2. 19. U.K. Ministry of Agriculture and Fisheries.

Bowler, D.E., and Benton, T.G. 2005. Causes and consequences of animal dispersal strategies: London: Chapman and Hall. 583 pp.

Bull, B., Francis, R.I.C.C., Dunn, A., McKenzie, A., Gilbert, D.J., Smith, M.H., Bain, R., and Fu, D. 2012. CASAL (C++ algorithmic stock assessment laboratory): CASAL user manual (v2.30). NIWA Tech. Rep. 135. 280 p.

Butterworth, D.S., and Punt, A.E. 1999. Experiences in the evaluation and implementation of management procedures. ICES J. Mar. Sci. 56: 985-998.

Cadrin, S.X, and Secor, D. 2009. Accounting for spatial population structure in stock

Carruthers, T.R., McAllister, M.K., and Taylor, N.G. 2011. Spatial surplus production assessment: past, present, and future. In The future of fisheries science in North America. modeling of Atlantic tunas and billfish. Ecol. Appl. 21: 2734-2755. Edited by R.J. Beamish and B.J. Rothschild. Springer Publishing. pp. 405-426. doi: 10.1007/978-1-4020-9210-7_22.

Ciannelli, L., Fisher, J.A.D., Skern-Mauritzen, M., Hunsicker, M.E., Hidalgo, M., Frank, 
802 Cope, J.M., and Punt, A.E. 2011. Reconciling stock assessment and management scales under 803 conditions of spatially varying catch histories. Fish. Res. 107: 22-38. doi: 10.1016/j.fishres.2010.10.002.

805 de Moor, C.L., and Butterworth, D.S. 2015. Assessing the South African sardine resource: two 806 stocks rather than one? Afr. J. Marine Sci. 37(1): 41-51.

807 Fahrig, L. 1993. Effect of fish movement and fleet spatial behaviour on management of fish substocks. Nat. Resour. Model. 7(1): 37-56.

Fournier, D.A., Hampton, J., and Sibert, J.R. 1998. MULTIFAN-CL: a length-based, agestructured model for fisheries stock assessment, with application to South Pacific albacore, Thunnus alalunga. Can. J. Fish. Aquat. Sci. 55: 2105-2116.

812 Fournier, D.A., Skaug, H.J., Ancheta, J., Ianelli, J., Magnusson, A., Maunder, M.N., Nielsen, A., and Sibert, J. 2012. AD Model Builder: using automatic differentiation for statistical inference of highly parameterized complex nonlinear models. Optim. Method. Softw. 27: 233-249. doi: 10.1080/10556788.2011.597854.

Francis, R.I.C.C., and McKenzie, J.R. 2015. Assessment of the SNA1 stocks in 2013. New Zealand Fisheries Assessment Report 2015/76. 82p.

Fu, C., and Fanning, L.P. 2004. Spatial considerations in the management of Atlantic cod off

820 Geromont, H.F., and Butterworth, D.S. 2015. Complex assessments or simple management procedures for efficient fisheries management: a comparative study. ICES J. Mar. Sci. 72(1): 262-274. 
823 Goethel, D.R., Quinn, T.J., II, and Cadrin, S.X. 2011. Incorporating spatial structure in stock

824 assessment: movement modelling in marine fish population dynamics. Rev. Fish. Sci. 19: 119-136. doi: 10.1080/10641262.2011.557451.

826 Goethel, D.R., Legault, C.M., and Cadrin, S.X. 2015. Testing the performance of a spatially explicit tag-integrated stock assessment model of yellowtail flounder (Limanda ferruginea) through simulation analysis. Can. J. Fish. Aquat. Sci. 72(1): 164-177. doi: 10.1139/cjfas-2014-0244.

Goethel, D.R., Kerr, L.A., and Cadrin, S.X. 2016. Incorporating spatial population structure into the assessment-management interface of marine resources. In Management science in fisheries: an introduction to simulation-based methods. Edited by C.T.T. Edwards and

Grandin, C.J., Hicks, A.C., Berger, A.M., Edwards, A.M., Taylor, N., Taylor, I.G., and Cox, S. 2016. Status of the Pacific Hake (whiting) stock in U.S. and Canadian waters in 2016. Prepared by the Joint Technical Committee of the U.S. and Canada Pacific Hake/Whiting

840 Hampton, J., and Fournier, D.A. 2001. A spatially disaggregated, length-based, age-structured population model of yellowfin tuna (Thunnus albacares) in the western and central Pacific Ocean. Mar. Freshwater Res. 52: 937-963.

843 Hanselman, D.H., Heifetz, J., Echave, K.B., and Dressel, S.C. 2015. Move it or lose it: movement and mortality of sablefish tagged in Alaska. Can. J. Fish. Aquat. Sci. 72: 238251. 
846 Hart, D.R. 2001. Individual-based yield-per-recruit analysis, with an application to the Atlantic sea scallop Placopecten magellanicus. Can. J. Fish. Aquat. Sci. 58: $2351-2358$.

Hart, D.R. 2003. Yield- and biomass-per-recruit analysis for rotational fisheries, with an application to the Atlantic sea scallop (Placopecten magellanicus). Fish. Bull. 101: 44-57.

Hilborn, R. 2002. The dark side of reference points. Bull. Mar. Sci. 70(2): 403-408.

Hjort, J. 1914. Fluctuations in the great fisheries of northern Europe. Rapp. P.-v. Reun.-Cons. Int. Explor. Mer. 20: 1-228.

Hoshino, E., Milner-Gulland, E.J., and Hillary, R.M. 2014. Why model assumptions matter for natural resource management: interactions between model structure and life histories in fishery models. J. Appl. Ecol. 51: 632-641.

Karnauskas, M., Walter, J.F., and Paris, C.B. 2013. Use of the Connectivity Modeling System to estimate movements of red snapper (Lutjanus campechanus) recruits in the northern Gulf

864 Kerr, L.A., Cadrin, S.X., and Secor, D.H. 2010b. The role of spatial dynamics in the stability, of Mexico. NOAA NMFS SEFSC. SEDAR31-AW10.

Kerr, L.A., Cadrin, S.X., and Secor, D.H. 2010a. Simulation modelling as a tool for examining resilience, and productivity of an estuarine fish population. Ecol. Appl. 20: 497-507.

Kerr, L.A., and Goethel, D.R. 2014. Simulation modelling as a tool for synthesis of stock identification information. In Stock identification methods: an overview. Edited by S.X. 
Cadrin, L.A. Kerr, and S. Mariani. Elsevier Science and Technology, Burlington, MA. pp. 501-533. doi: 10.1016/B978-0-12-397003-9.00021-7.

Kerr, L.A., Cadrin, S.X., and Kovach, A.I. 2014. Consequences of a mismatch between biological and management units on our perception of Atlantic cod off New England. ICES J. Mar. Sci. 71(6): 1366-1381.

Kritzer, J.P., and Sale, P.F. 2004. Metapopulation ecology in the sea: from Levins' model to marine ecology and fisheries science. Fish Fish. 5: 131-140. doi: 10.1111/j.14672979.2004.00131.x.

Kritzer, J.P., and Liu, O.W. 2014. Fishery management strategies for addressing complex spatial structure in marine fish stocks. In Stock identification methods: an overview. Edited by S.X. Cadrin, L.A. Kerr, and S. Mariani. Elsevier Science and Technology, Burlington, MA. pp. 29-57.

Li, Y., Bence, J.R., and Brenden, T.O. 2015. An evaluation of alternative assessment approaches for intermixing fish populations: a case study with Great Lakes lake whitefish. ICES. J. Mar. Sci. 72(1): 70-81. doi: 10.1093/icesjms/fsu057

Ling, S., and Milner-Gulland, E.J. 2008. When does spatial structure matter in models of wildlife harvesting? J. Appl. Ecol. 45: 63-71.

McGilliard, C.R., Punt, A.E., Methot, R.D., and Hilborn, R. 2015. Accounting for marine reserves using spatial stock assessments. Can. J. Fish. Aquat. Sci. 72: 262-280.

Mchich, R., Charouki, N., Auger, P., Raissi, N., and Ettahiri, O. 2006. Optimal spatial distribution of the fishing effort in a multi fishing zone model. Ecol. Model. 197: 274-280. 
890 Methot, R.D., and Wetzel, C.R. 2013. Stock Synthesis: a biological and statistical framework for 891 fish stock assessment and fishery management. Fish. Res. 142: 86-99. doi: 10.1016/j.fishres.2012.10.012.

Miller, T.J., and Andersen, P.K. 2008. A finite-state continuous-time approach for inferring regional migration and mortality rates from archival tagging and conventional tagrecovery experiments. Biometrics. 64: 1196-1206.

Patterson, W.F. 2007. A review of movement in Gulf of Mexico red snapper: implications for population structure. Am. Fish. Soc. Symp. 60: 221-335.

898 Pelletier, D., and Mahévas, S. 2005. Spatially explicit fisheries simulation models for policy evaluation. Fish and Fish. 6: 307-349.

900 Pincin, J.S., and Wilberg, M.J. 2012. Surplus production model accuracy in populations 901 affected by a no-take marine protected area. Mar. Coast. Fish. 4: 511-525.

902 Porch, C. 2003. VPA-2Box (ver. 3.01). Ass. Prog. Doc. ICCAT.

903 Porch, C., Kleiber, P., Turner, S. C., Sibert, J., Bailey, R. B., and Cort, J. L. 1998. The efficacy of VPA models in the presence of complicated movement patterns. Collect. Vol. Sci. Pap. ICCAT. 50: 591-622.

906 Punt, A.E., and Cui, G. 2000. Including spatial structure when conducting yield-perrecruit analysis. Australian society for fish biology workshop proceedings, pp. 176-182. September, 1999. Bendigo, Victoria, Australia. of marine fisheries. Am. Fish. Soc. Symp. 42: 133-154. 
911 Punt, A.E., Haddon, M., and Tuck, G.N. 2015. Which assessment configurations perform

912 best in the face of spatial heterogeneity in fishing mortality, growth, and

913 recruitment? A case study based on pink ling in Australia. Fish. Res. 168: 85-99.

914 R Core Team. 2012. R: A language and environment for statistical computing. R

915 Foundation for Statistical Computing, Vienna, Austria. ISBN 3-900051- 07-0,

$916 \quad$ URL http://www.R-project.org/.

917 Reiss, H., Hoarau, G., Dickey-Collas, M., and Wolff, W.J. 2009. Genetic population structure of

918 marine fish: mismatch between biological and fisheries management units. Fish Fish.

919 10(4): 361-395.

920 Reuchlin-Hugenholtz, E., Shackell, N.L., and Hutchings, J.A. 2015. The potential for spatial

921 distribution indices to signal thresholds in marine fish biomass. PLoS ONE. 10(3):

$922 \quad \mathrm{e} 0120500$.

923 Reuchlin-Hugenholtz, E., Shackell, N.L., and Hutchings, J.A. 2016. Spatial reference points for 924 groundfish. ICES J. Mar. Sci. doi: 10.1093/icesjms/fsw123.

925 Rideout, R.M., and Tomkiewicz, J. 2011. Skipped spawning in fishes: more common than you 926 might think. Mar. Coast. Fish. 3: 176-189.

927 Rooker, J.R., Secor, D.H., De Metrio, G., Schloesser, R., Block, B.A., and Neilson, J.D. 2008.

928 Natal homing and connectivity in Atlantic bluefin tuna populations. Science. 322: $742-$

929744.

930 Sanchirico, J.N., and Wilen, J.E. 2001. Dynamics of spatial exploitation: a

931 metapopulation approach. Nat. Resour. Model. 14(3): 391-418. 
932 Sanchirico, J.N., and Wilen, J.E. 2005. Optimal spatial management of renewable

933 resources: matching policy scope to ecosystem scale. J. Environ. Econ. Manag.

$934 \quad 50: 23-46$.

935 SEDAR (Southeast Data, Assessment, and Review). 2015. Stock assessment of red 936 snapper in the Gulf of Mexico 1872-2013 — with provisional 2014 landings. Gulf 937 of Mexico Science and Statistical Committee. Tampa, FL.

938 Sinclair, M. 1988. Marine populations: an essay on population regulation and speciation. 939 University of Washington Press, Seattle, WA. 252pp.

940 Steneck, R.S., and Wilson, J.A. 2010. A fisheries play in an ecosystem theatre: challenges 941 of managing ecological and social drivers of marine fisheries at multiple spatial 942 scales. Bull. Mar. Sci. 86(2): 387-411.

943 Takashina, N., and Mougi, A. 2015. Maximum sustainable yields from a spatially-explicit 944 harvest model. J. Theor. Biol. 383: 87-92. doi: 10.1016/j.jtbi.2015.07.028.

945 Thorson, J.T., Fonner, R., Haltuch, M.A., Ono, K., and Winker, H. 2016. Accounting for 946 spatio-temporal variation and fisher targeting when estimating abundance from 947 multispecies fishery data. Can. J. Fish. Aquat. Sci. doi: 10.1139/cjfas-2015-0598.

948 Truesdell, S.B., Hart, D.B., and Chen, Y. 2016. Effects of spatial heterogeneity in growth 949 and fishing effort on yield-per-recruit models: an application to the US Atlantic 950 sea scallop fishery. ICES J. Mar. Sci. 73(4): 1062-1073.

951 Tuck, G.N., and Possingham, H.P. 1994. Optimal harvesting strategies for a metapopulation. 952 Bull. Math. Biol. 56: 107-127.

953 Turchin, P. 1998. Quantitative analysis of movement: measuring and modelling population 954 redistribution in animals and plants. Sinauer Associates, Inc., Sunderland, MA, USA. 
955 Wilberg, M.J., Irwin, B.J., Jones, M.L., and Bence, J.R. 2008. Effects of source-sink dynamics 956 on harvest policy performance for yellow perch in southern Lake Michigan. Fish. Res. 957 94: 282-289.

958 Wilen, J.E. 2004. Spatial management of fisheries. Mar. Resour. Econ. 19: 7-19.

959 Ying, Y., Chen, Y., Lin, L., and Gao, T. 2011. Risks of ignoring fish population spatial structure 960 in fisheries management. Can. J. Fish. Aquat. Sci. 68: 2101-2120. doi: 10.1139/f2011$961 \quad 116$.

962

963 


\section{Tables}

965 Table 1: Glossary of terms used throughout the article.

966

Term

Spatial Population Structure

Connectivity

Area

Population

System-wide

Panmictic

Single Population with Spatial

Heterogeneity

Metapopulation

Natal Homing

Unidirectional Movement

Bidirectional Movement

Spawning Migration

Natal Return

Harvest Rate
Definition

The spatiotemporal distribution of a resource resulting from environmental or ecosystem interactions (i.e., connectivity) and reproductive dynamics.

Movement of individuals among geographic areas at any life stage (e.g., larval or adult).

A geographic unit representing the spatial extent over which a homogenous fishing mortality acts. Depending on the type of population structure, an area may contain a segment of a single population, an entire population or segments of multiple populations.

A self-reproducing biological entity within which all fish are able to reproductively mix resulting in a single SSB that determines population-specific recruitment values based on a unique stock-recruit function.

The entire spatial domain of the model. A single, unit population with no spatial heterogeneity.

A single population with abundance distributed over multiple areas.

A network of populations each with unique stock-recruit relationships, but which can reproductively mix. It is assumed that environmental factors drive demographic rates. A population structure wherein multiple populations overlap spatially, but do not reproductively mix. Fish always retain the life history characteristics of their natal population, which assumes that genetics drive demographic parameters. Movement among areas is only allowed in one direction (e.g., source-sink dynamics). Movement is allowed among all areas.

An instantaneous migration at the time of spawning that allows a fish to reside outside of its natal area throughout the year, but still add to the SSB of its natal population. A return migration at a specific age (i.e., $\mathrm{a}_{\mathrm{RET}}$ ) that emulates an ontogenetic migration. The fraction of the biomass that is harvested within a given area (i.e., yield/biomass). 
976 Table 2: Input parameters for a midwater pelagic, hake-like species used to evaluate $B R P_{-} D e v$

977 and $H L_{-}$App models. Abundance and recruitment are in 1000s of fish, weight is in $\mathrm{kg}$, $978 \quad$ and SSB is in metric tons.

979

\begin{tabular}{cccrcc}
\hline Age & Selectivity & Maturity & $\begin{array}{c}\text { Initial } \\
\text { Abundance }\end{array}$ & M & Weight \\
\hline 1 & 0.00 & 0.00 & $3,125,000$ & 0.226 & 0.101 \\
2 & 0.12 & 0.12 & $2,538,636$ & 0.226 & 0.273 \\
3 & 0.54 & 0.54 & $2,062,295$ & 0.226 & 0.377 \\
4 & 0.71 & 0.71 & $1,675,333$ & 0.226 & 0.473 \\
5 & 0.87 & 0.87 & $1,360,979$ & 0.226 & 0.545 \\
6 & 1.00 & 1.00 & $1,105,610$ & 0.226 & 0.622 \\
7 & 1.00 & 1.00 & 898,157 & 0.226 & 0.674 \\
8 & 1.00 & 1.00 & 729,630 & 0.226 & 0.754 \\
9 & 1.00 & 1.00 & 592,725 & 0.226 & 0.805 \\
10 & 1.00 & 1.00 & 481,508 & 0.226 & 0.833 \\
11 & 1.00 & 1.00 & 391,159 & 0.226 & 0.909 \\
12 & 1.00 & 1.00 & 317,764 & 0.226 & 0.952 \\
13 & 1.00 & 1.00 & 258,139 & 0.226 & 0.938 \\
14 & 1.00 & 1.00 & 209,703 & 0.226 & 0.918 \\
$15+$ & 1.00 & 1.00 & 170,355 & 0.226 & 0.982 \\
\hline \hline $\mathbf{R}_{0}$ & $3,125,000$ & SSB $_{0}$ & $2,397,000$ & Steepness & 0.814 \\
\hline
\end{tabular}


981 Table 3: Scenario list for the Move+Prod subset of BRP_Dev models. For natal return and

982 spawning migration models, adult residency actually corresponds to the rate of return.

\begin{tabular}{|c|c|c|c|c|c|c|c|c|}
\hline \multirow[b]{2}{*}{ Scenario } & \multirow{2}{*}{$\begin{array}{l}\text { Population } \\
\text { Structure }\end{array}$} & \multicolumn{2}{|c|}{ Residency Level } & \multirow[b]{2}{*}{ None } & \multicolumn{4}{|c|}{ Movement Type } \\
\hline & & Adult & Larval & & Unidirectional & Bidirectional & $\begin{array}{l}\text { Spawning } \\
\text { Migration }\end{array}$ & $\begin{array}{c}\text { Natal } \\
\text { Return }\end{array}$ \\
\hline 1 & 1 Population, Panmictic & all & all & $\mathbf{x}$ & & & & \\
\hline 2 & 1 Population, 2 Areas & all & all & $\mathbf{x}$ & & & & \\
\hline 3 & 1 Population, 2 Areas & high & low & & $\mathbf{x}$ & & & \\
\hline 4 & 1 Population, 2 Areas & low & high & & $\mathbf{x}$ & & & \\
\hline 5 & 1 Population, 2 Areas & high & high & & $\mathbf{x}$ & & & \\
\hline 6 & 1 Population, 2 Areas & low & low & & $\mathbf{x}$ & & & \\
\hline 7 & 1 Population, 2 Areas & high & low & & & $\mathbf{x}$ & & \\
\hline 8 & 1 Population, 2 Areas & low & high & & & $\mathbf{x}$ & & \\
\hline 9 & 1 Population, 2 Areas & high & high & & & $\mathbf{x}$ & & \\
\hline 10 & 1 Population, 2 Areas & low & low & & & $\mathbf{x}$ & & \\
\hline 11 & Metapopulation & all & all & $\mathbf{x}$ & & & & \\
\hline 12 & Metapopulation & high & low & & $\mathbf{x}$ & & & \\
\hline 13 & Metapopulation & low & high & & $\mathbf{x}$ & & & \\
\hline 14 & Metapopulation & high & high & & $\mathbf{x}$ & & & \\
\hline 15 & Metapopulation & low & low & & $\mathbf{x}$ & & & \\
\hline 16 & Metapopulation & high & low & & & $\mathbf{x}$ & & \\
\hline 17 & Metapopulation & low & high & & & $\mathbf{x}$ & & \\
\hline 18 & Metapopulation & high & high & & & $x$ & & \\
\hline 19 & Metapopulation & low & low & & & $x$ & & \\
\hline 20 & Natal Homing & high & low & & $\mathbf{x}$ & & $\mathbf{x}$ & \\
\hline 21 & Natal Homing & low & high & & $\mathbf{x}$ & & $\mathbf{x}$ & \\
\hline 22 & Natal Homing & high & high & & $x$ & & $\mathbf{x}$ & \\
\hline 23 & Natal Homing & low & low & & $\mathbf{x}$ & & $\mathbf{x}$ & \\
\hline 24 & Natal Homing & high & low & & $\mathbf{x}$ & & & \\
\hline 25 & Natal Homing & low & high & & $\mathbf{x}$ & & & \\
\hline 26 & Natal Homing & high & high & & $\mathbf{x}$ & & & \\
\hline 27 & Natal Homing & low & low & & $\mathbf{x}$ & & & \\
\hline 28 & Natal Homing & high & low & & & $\mathbf{x}$ & $\mathbf{x}$ & \\
\hline 29 & Natal Homing & low & high & & & $\mathbf{x}$ & $\mathbf{x}$ & \\
\hline 30 & Natal Homing & high & high & & & $\mathbf{x}$ & $\mathbf{x}$ & \\
\hline 31 & Natal Homing & low & low & & & $\mathbf{x}$ & $\mathbf{x}$ & \\
\hline 32 & Natal Homing & high & low & & & $x$ & & \\
\hline 33 & Natal Homing & low & high & & & $x$ & & \\
\hline 34 & Natal Homing & high & high & & & $\mathbf{x}$ & & \\
\hline 35 & Natal Homing & low & low & & & $x$ & & \\
\hline 36 & Natal Homing & high & low & & $\mathbf{x}$ & & & $x$ \\
\hline 37 & Natal Homing & low & high & & $\mathbf{x}$ & & & $\mathbf{x}$ \\
\hline 38 & Natal Homing & high & high & & $\mathbf{x}$ & & & $\mathbf{x}$ \\
\hline 39 & Natal Homing & low & low & & $x$ & & & $\mathbf{x}$ \\
\hline 40 & Natal Homing & high & low & & & $x$ & & $\mathbf{x}$ \\
\hline 41 & Natal Homing & low & high & & & $\mathbf{x}$ & & $\mathbf{x}$ \\
\hline 42 & Natal Homing & high & high & & & $x$ & & $\mathbf{x}$ \\
\hline 43 & Natal Homing & low & low & & & $\mathbf{x}$ & & $\mathbf{x}$ \\
\hline
\end{tabular}


988 Table 4: Qualitative summary of $B R P \_$Dev results describing the relative value of each factor (SSB, yield, and harvest rate) for various population structures and movement types. Results are averaged across movement levels within each movement type to provide an overview of results. Qualitative values (low, medium or high) represent relative comparisons for that factor across population structure and movement types within that geographic area (i.e., system-wide or area-specific).

\begin{tabular}{|c|c|c|c|c|c|}
\hline Population Structure & Movement Type & Factor & System-Wide & Area 1 & Area 2 \\
\hline \multirow{3}{*}{$\begin{array}{l}1 \text { Population, } \\
\text { Panmictic }\end{array}$} & \multirow{3}{*}{ No Movement } & SSB & High & - & - \\
\hline & & Yield & High & - & - \\
\hline & & uMSY & Moderate & - & - \\
\hline \multirow{6}{*}{$\begin{array}{l}1 \text { Population, } \\
2 \text { Areas }\end{array}$} & \multirow{3}{*}{ Unidirectional } & SSB & High & High & Low \\
\hline & & Yield & High & High & Low \\
\hline & & UMSY & Moderate & Moderate/High & Moderate/Low \\
\hline & \multirow{3}{*}{ Bidirectional } & SSB & High & Moderate/High & Moderate \\
\hline & & Yield & High & Moderate & Moderate \\
\hline & & uMSY & Moderate & Moderate & Moderate \\
\hline \multirow{6}{*}{ Metapopulation } & \multirow{3}{*}{ Unidirectional } & SSB & Moderate/Low & Moderate & Moderate/Low \\
\hline & & Yield & Moderate/Low & High & Low \\
\hline & & uMSY & Moderate/High & High & Low \\
\hline & \multirow{3}{*}{ Bidirectional } & SSB & High & Moderate & Moderate/High \\
\hline & & Yield & High & Moderate/High & Moderate/Low \\
\hline & & uMSY & Moderate & High & Moderate/Low \\
\hline \multirow{12}{*}{ Natal Homing } & \multirow{3}{*}{$\begin{array}{c}\text { Unidirectional, } \\
\text { Spawning Migration }\end{array}$} & SSB & High & Moderate/Low & Moderate/High \\
\hline & & Yield & High & Moderate/Low & Moderate \\
\hline & & uMSY & Moderate & Moderate/Low & Moderate/High \\
\hline & \multirow{3}{*}{$\begin{array}{c}\text { Bidirectional, } \\
\text { Spawning Migration }\end{array}$} & SSB & High & Moderate/Low & Moderate/High \\
\hline & & Yield & High & Low & Moderate/High \\
\hline & & uMSY & Moderate & Moderate/Low & Moderate/High \\
\hline & \multirow{3}{*}{$\begin{array}{l}\text { Unidirectional, } \\
\text { Natal Return }\end{array}$} & SSB & Moderate & Moderate/Low & Moderate/High \\
\hline & & Yield & Moderate & Low & Moderate \\
\hline & & uMSY & Moderate & Moderate/Low & Moderate/High \\
\hline & \multirow{3}{*}{$\begin{array}{l}\text { Bidirectional, } \\
\text { Natal Return }\end{array}$} & SSB & Moderate & Moderate/Low & Moderate/High \\
\hline & & Yield & Moderate & Low & Moderate/high \\
\hline & & uMSY & Moderate & Low & Moderate/High \\
\hline
\end{tabular}


996 Table 5: Qualitative summary of $H L_{-}$App results describing the relative rate of occurrence

997 (compared to results of other spatial structure scenarios) for each factor (i.e., depletion,

998 foregone yield or underutilization) and each of the true and assumed population

999 structure combinations. Results are averaged across movement types and geographic

1000 areas within any given assumed to true population structure comparison in order to

1001 provide a qualitative overview of results. When true and assumed spatial structures

1002 are identical, results compare different movement assumptions (e.g., unidirectional

1003 versus bidirectional movement) for the given population structure.

1004

\begin{tabular}{|c|c|c|c|c|c|}
\hline & \multirow[b]{2}{*}{ Factor } & \multicolumn{4}{|c|}{ True Population Structure } \\
\hline & & $\begin{array}{l}1 \text { Population, } \\
\text { Panmictic }\end{array}$ & $\begin{array}{c}1 \text { Population, } \\
2 \text { Areas }\end{array}$ & Metapopulation & Natal Homing \\
\hline \multirow{3}{*}{$\begin{array}{l}1 \text { Population, } \\
\text { Panmictic }\end{array}$} & Depletion & - & Moderate & Moderate/High & Low \\
\hline & Foregone Yield & - & Low & High & Low \\
\hline & Underutilization & - & Low & High & Low \\
\hline \multirow{3}{*}{$\begin{array}{l}1 \text { Population, } \\
2 \text { Areas }\end{array}$} & Depletion & Low & Low & Moderate & Low \\
\hline & Foregone Yield & Low & Low & Moderate & Low \\
\hline & Underutilization & Low & Low & High & Low \\
\hline \multirow{3}{*}{ Metapopulation } & Depletion & Low & Moderate/High & Moderate & High \\
\hline & Foregone Yield & Low & High & High & Moderate \\
\hline & Underutilization & Low & High & Moderate & High \\
\hline \multirow{3}{*}{ Natal Homing } & Depletion & Low & Low/Moderate & Moderate & Low \\
\hline & Foregone Yield & Low & Low & Moderate & Low \\
\hline & Underutilization & Low & Low & High & Low \\
\hline
\end{tabular}




\section{Figures}

1007

1008 Figure 1: Outline of the two-stage generalized simulation model. MSY-based BRPs were input harvest rate or yield level. Stages were run independently.

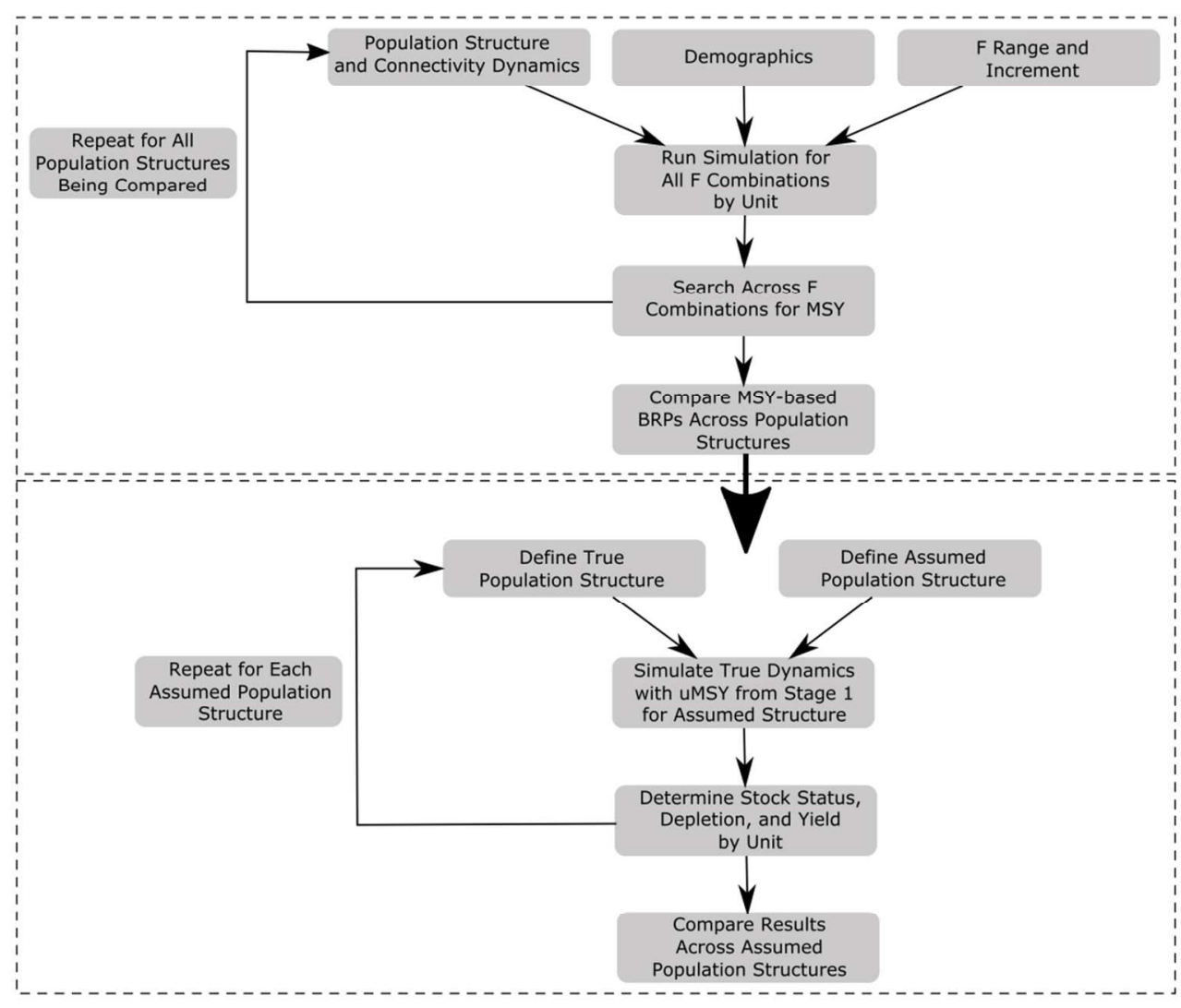

\section{Stage 1}

\section{Stage 2}


1014 Figure 2: Spatial (A) and spatiotemporal (B) dynamics of the simulation model (see Equations 1015 1-5 and associated text for a description of terms). Large circles represent geographic 1016 areas within which multiple populations can mix (for spatial heterogeneity smaller 1017 circles represent areas within a single population). Mixing (dark overlap regions) is 1018 depicted as taking place in partial areas for illustrative purposes, but actually takes 1019 place across the extent of the given geographic area. Dotted lines illustrate movement, while narrow solid lines represent recruitment. The small circles in the bottom panel (B) represent the segment of a population (population is denoted by the subscript) outside its natal area, which overlaps with the natal population of the geographic area (large circles; area is represented by the superscript).
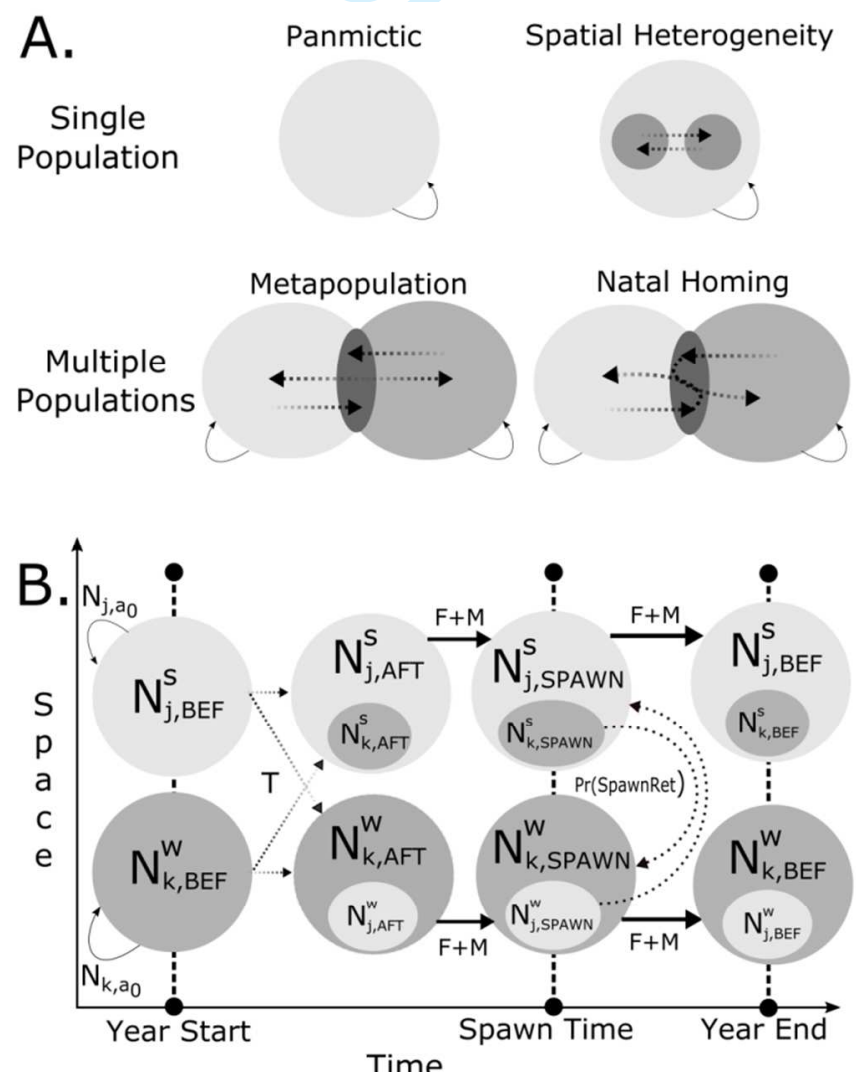
1026 Figure 3: Results from the Move+Prod subset of BRP_Dev models illustrating MSY-based reference points. MSY and $\mathrm{SSB}_{\mathrm{MSY}}$ are in 1000 s of metric tons, while $\mathrm{u}_{\mathrm{MSY}}$ is the harvest rate (yield/biomass). Scenarios are grouped by the general type of spatial population structure used in the simulation model (specifics of each scenario are shown in Table 3). Values are provided by area and system-wide (i.e., total summed across areas).

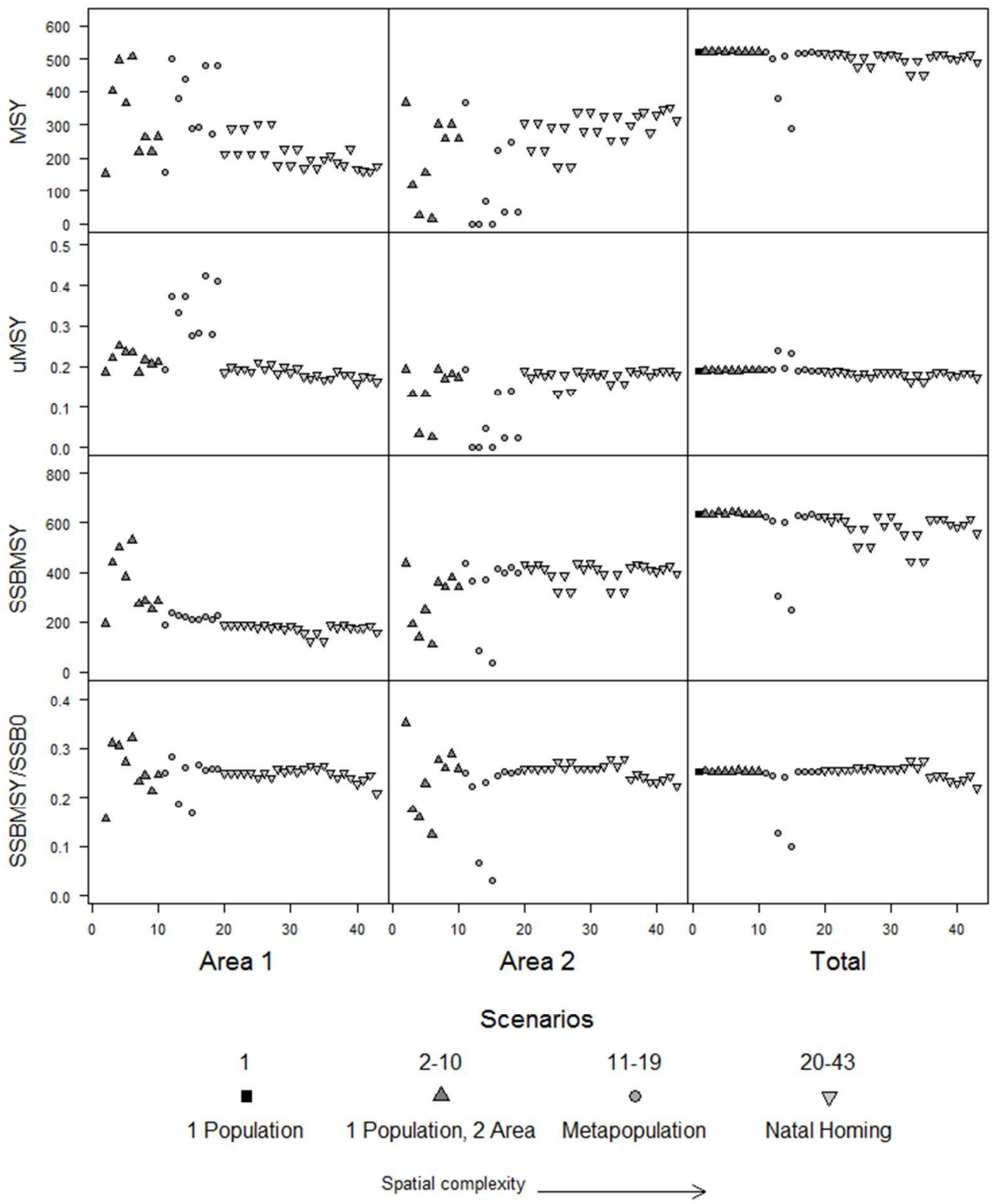


1033 Figure 4: Results from $H L_{-}$App models demonstrating stock status relative to the true $\mathrm{SSB}_{\mathrm{MSY}}$ (i.e., $\mathrm{SSB}_{\text {Terminal }} / \mathrm{SSB}_{\mathrm{MSYTrue}}$ ) assuming panmictic population structure. The true spatial population structure for each scenario is described by the x-axis tabular labels.

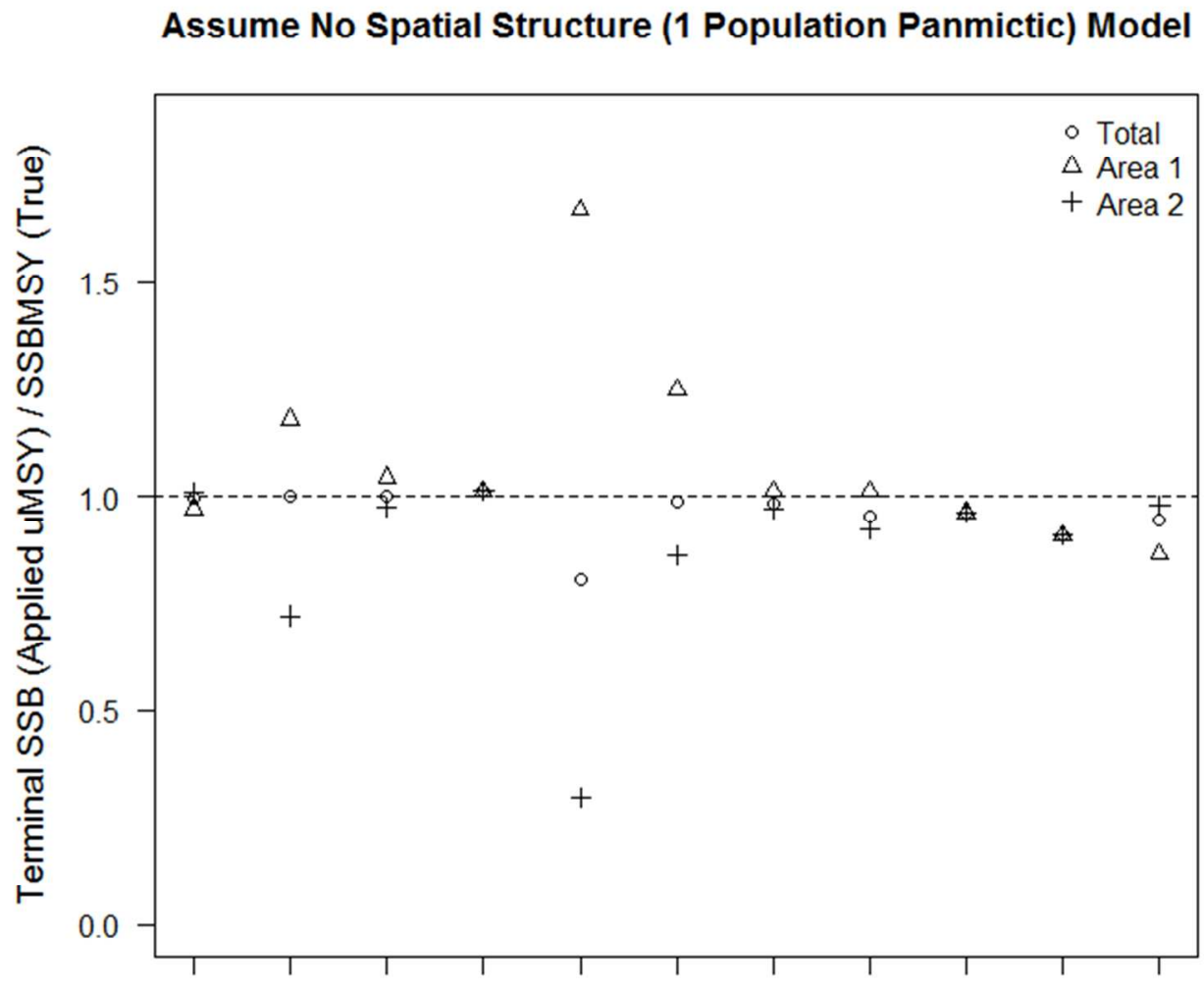

True Spatial Structure Scenario

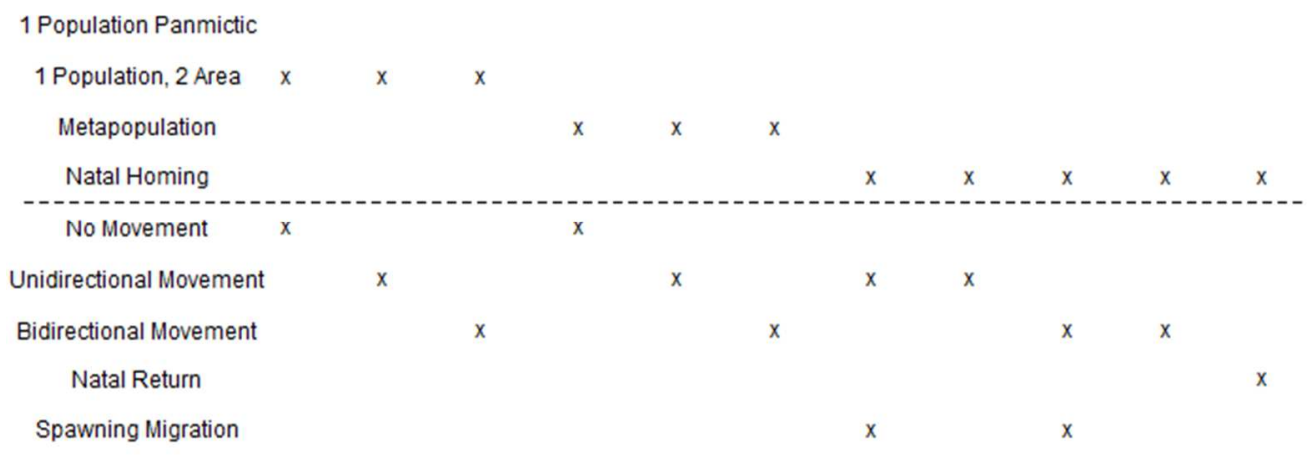


1039 Figure 5: Results from $H L_{-}$App models demonstrating stock status relative to the true $\mathrm{SSB}_{\mathrm{MSY}}$ (i.e., $\mathrm{SSB}_{\text {Terminal }} / \mathrm{SSB}_{\mathrm{MSYTrue}}$ ) assuming metapopulation structure with source-sink dynamics (i.e., unidirectional movement; left panel) and bidirectional movement (right panel). The true spatial population structure for each scenario is described by the $\mathrm{x}$-axis tabular labels. Values are provided by area and system-wide (i.e., total summed across areas).

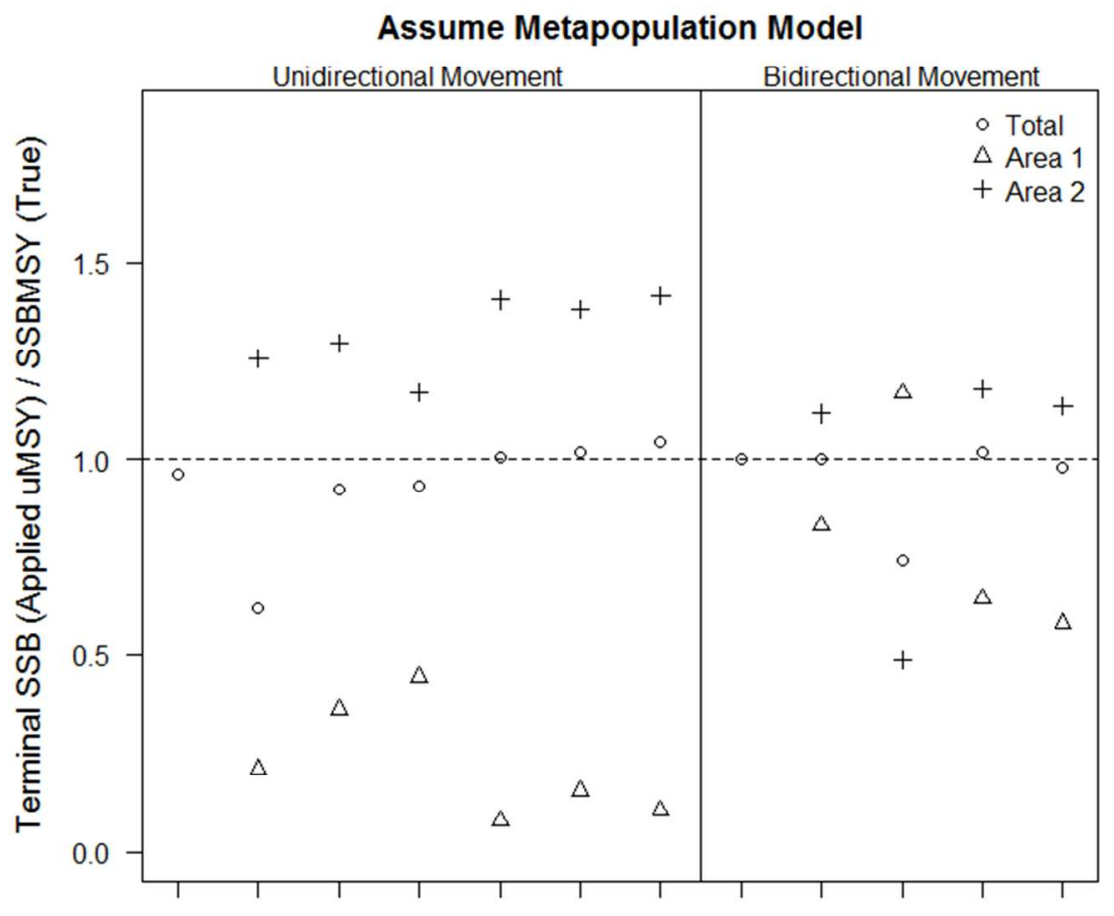

True Spatial Structure Scenario

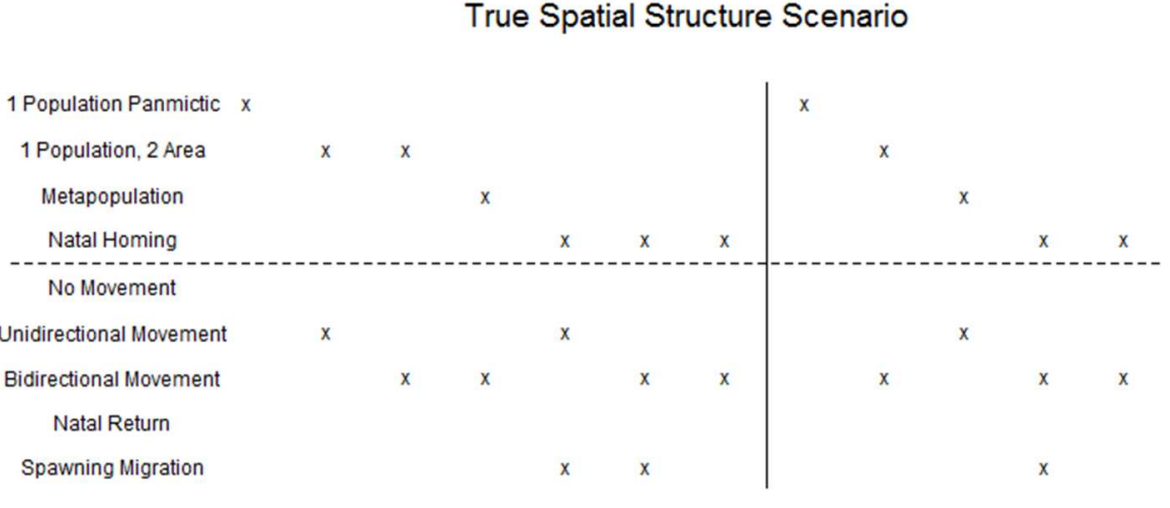


1047 Figure 6: Results from $H L_{-}$App models demonstrating stock status relative to the true $\mathrm{SSB}_{\mathrm{MSY}}$

1048 (i.e., $\mathrm{SSB}_{\text {Terminal }} / \mathrm{SSB}_{\mathrm{MSYTrue}}$ ) assuming natal homing population structure. The left

1049 hand panel illustrates results assuming bidirectional movement and spawning

1050 migrations (except the last two scenarios, which assume no spawning migration),

1051 while the right hand panel displays results assuming natal return. The true spatial

1052 population structure for each scenario is described by the x-axis tabular labels.

1053 Values are provided by area and system-wide (i.e., total summed across areas).

1054

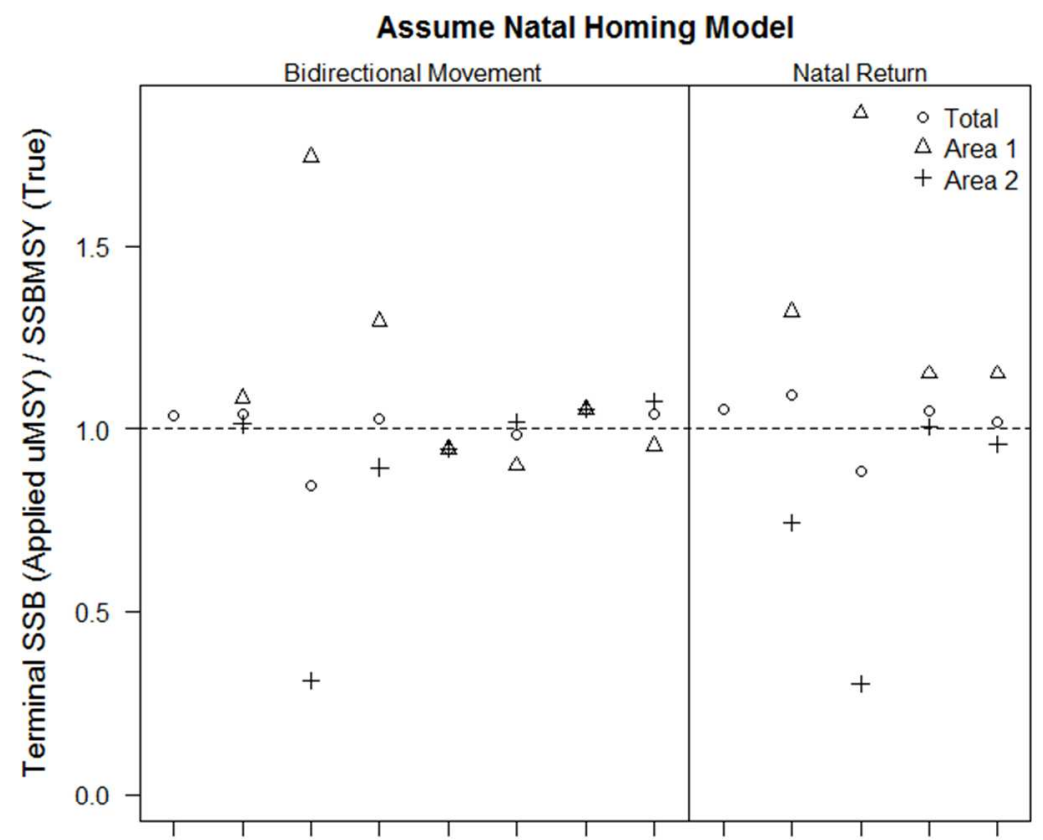

True Spatial Structure Scenario

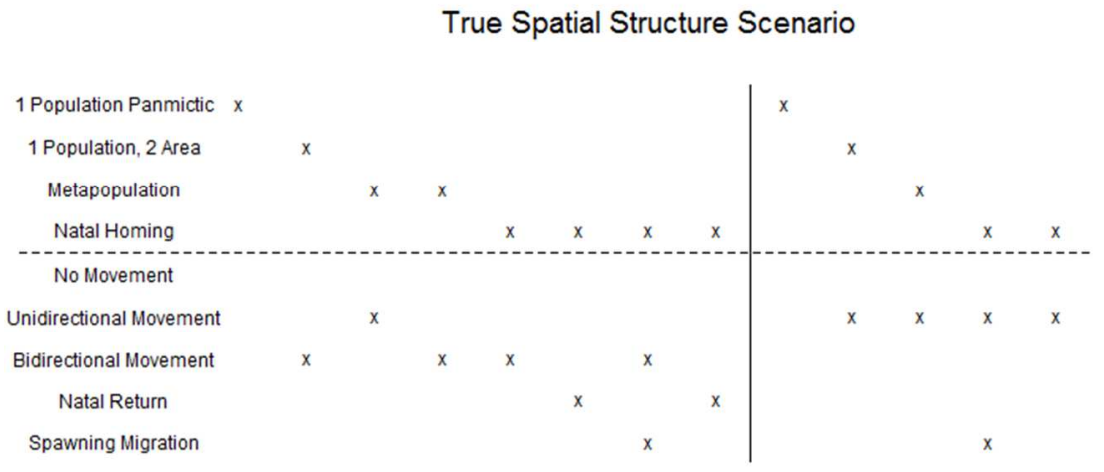


1056 Figure 7: Results from Snapper_Uneven_Eff scenarios demonstrating stock status relative to the true $\mathrm{SSB}_{\mathrm{MSY}}$ (i.e., $\mathrm{SSB}_{\text {Terminal }} / \mathrm{SSB}_{\mathrm{MSYTrue}}$ ) assuming panmictic stock structure and allowing a nonhomogeneous distribution of effort (i.e., harvest rate in area 1 is halved and harvest rate in area 2 is increased until the total system-wide harvest rate reaches the desired panmictic $\mathrm{u}_{\mathrm{MSY}}$ ). The true spatial population structure for each scenario is described by the $\mathrm{x}$-axis tabular labels, where an asterisk represents the lowest residency rate (i.e., 80\%) scenario. Values are provided by area and system-wide (i.e., total summed across areas).

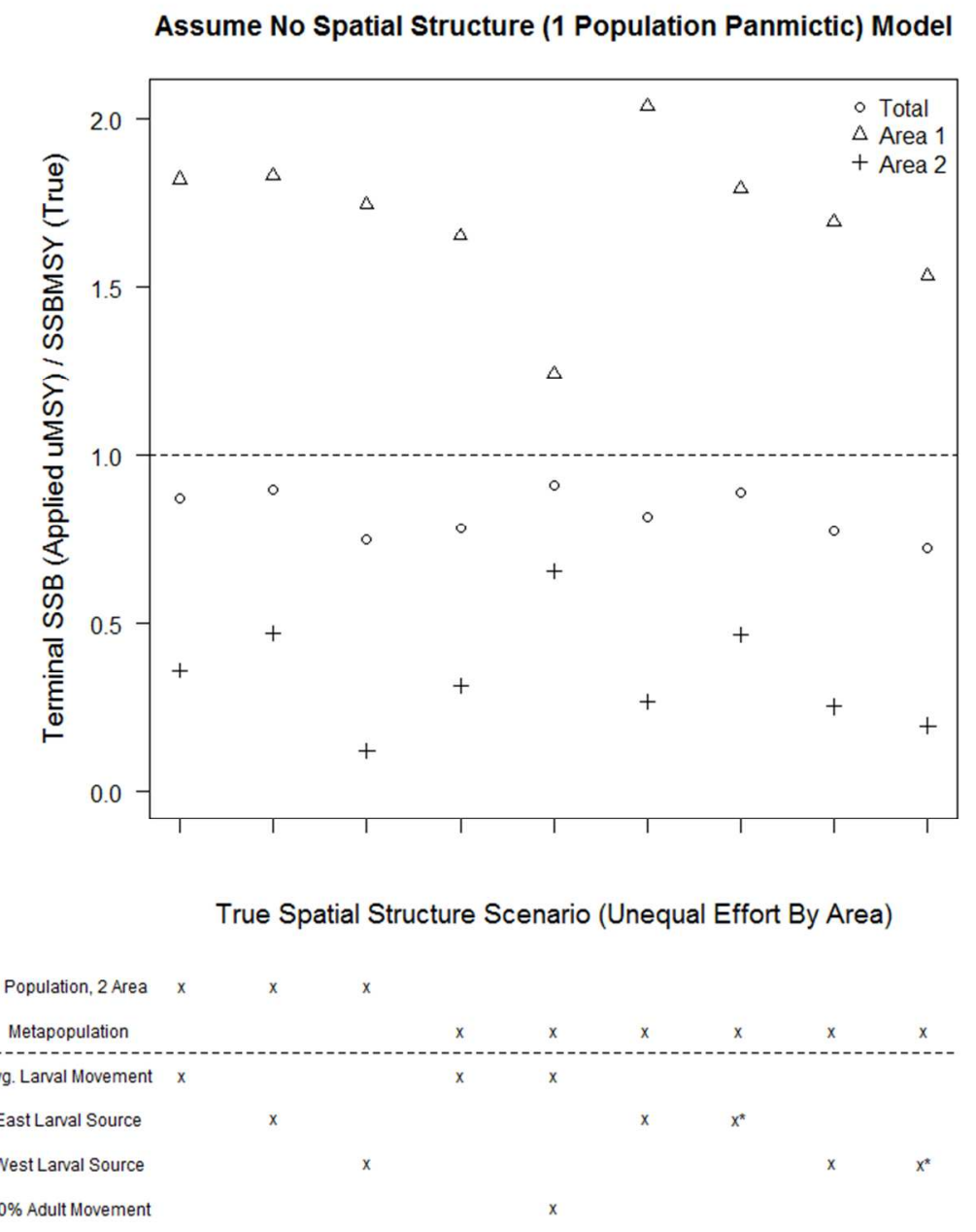

